\title{
La metrópolis del delta neerlandés. Crisis y actualización de un modelo urbano policéntrico.
}

\author{
Joan Moreno Sanz \\ Universidad Politécnica de Catalunya UPC-BarcelonaTECH \\ Estanislao Roca Blanch \\ Universidad Politécnica de Catalunya UPC-BarcelonaTECH
}

\begin{abstract}
La metrópolis del delta neerlandés. Crisis y actualización de un modelo urbano policéntrico (Resumen)

El Randstad-Holland, la aglomeración urbana neerlandesa, entra en crisis como modelo de ordenación urbana policéntrica en el último cuarto de siglo. A escala global, los procesos de integración política y económica europeos ponen a prueba la competitividad de la región frente a otros sistemas centralizados próximos. A escala local, se agudiza el conflicto entre los centros urbanos tradicionales y los nuevos corredores de transporte periféricos. En este contexto, las políticas de ordenación territorial en los Países Bajos se orientan hacia la integración de la movilidad y el patrón funcional del suelo con un doble objetivo: por un lado, mejorar la eficiencia de la red de transporte, y por el otro la promoción del modelo de ciudad compacta. El Randstad-Holland es refundado como la Deltametrópolis, un nuevo orden basado en la actualización del modelo policéntrico, a partir de un instrumento que pautará el futuro desarrollo de la metrópolis: la red de corredores nodales.
\end{abstract}

Palabras clave: policentrismo, red de transporte, ordenación territorial, Randstad-Holland

The Dutch Deltametropolis. Crisis and updating of a polycentric urban model (Abstract)

The Randstad-Holland, the Dutch urban agglomeration, goes into crisis as polycentric urban pattern in the latest quarter of a century. On a global scale, European integration processes, in a political and economic sense, test the competitiveness of the urban region in relation to other close centralist urban systems. On a local scale, the conflict between the traditional urban centers and the new peripheral transport corridors makes worse. In this context, the urban planning polices in the Netherlands are aimed at mobility and urban pattern integration in a dual purpose: Improving, on the one hand, the efficiency of the transport network and one the other hand, encouraging the compact city model. The Randstad-Holland is reestablished as the Deltametropool, a new urban model based on reviewed polycentric system. Nodal corridor in the transport network is the new urban tool that will provide guidelines for developing the urban-mobile metropolis.

Keywords: polycentrism, transport network, regional planning, Randstad-Holland 
El delta neerlandés es el territorio paradigmático de las redes (figura 1) desde las primeras etapas de consolidación de la actividad humana. La desembocadura de los ríos Rin, Mosa y Escalda era el nodo natural de confluencia de las rutas comerciales que conectaban los mercados báltico, centroeuropeo y británico. El desarrollo de la tecnología hidráulica permite además, el despliegue de un complejo sistema de arroyos y canales que funciona simultáneamente como red de transporte, patrón de drenaje y constituye la base de la estructura parcelaria. De este modo, la red acuática consolida y pauta el desarrollo de la red urbana mediante un sistema jerarquizado de puertos fluviales que gestionan las relaciones comerciales entre la ciudad y su región. Con la mejora de las infraestructuras de transporte, la aparición de nuevos medios de locomoción y el consecuente incremento de la movilidad regional $^{1}$, se pone de manifiesto la necesidad de crear nuevos instrumentos de planificación que permitan superar la escala local y reconozcan entidades territoriales superiores. En este sentido, el Randstad-Holland [Ciudad de margen], la aglomeración urbana del oeste neerlandés, es un sistema regional que ha perdurado en el tiempo y está constituido por un anillo urbano de carácter policéntrico dispuesto en torno a un vacío agrícola: el Groene Hart [Corazón Verde]. Los procesos de dispersión funcional que durante la segunda mitad del siglo $\mathrm{XX}$ han tenido lugar en el delta han desdibujado el contorno urbano ${ }^{2}$. Sin embargo, la imagen del Randstad-Holland como una cadena armónica de núcleos urbanos especializados se impone a una realidad territorial heterogénea de competencia nodal.

\section{Figura 1. Estructura administrativa y urbana de los Países Bajos}

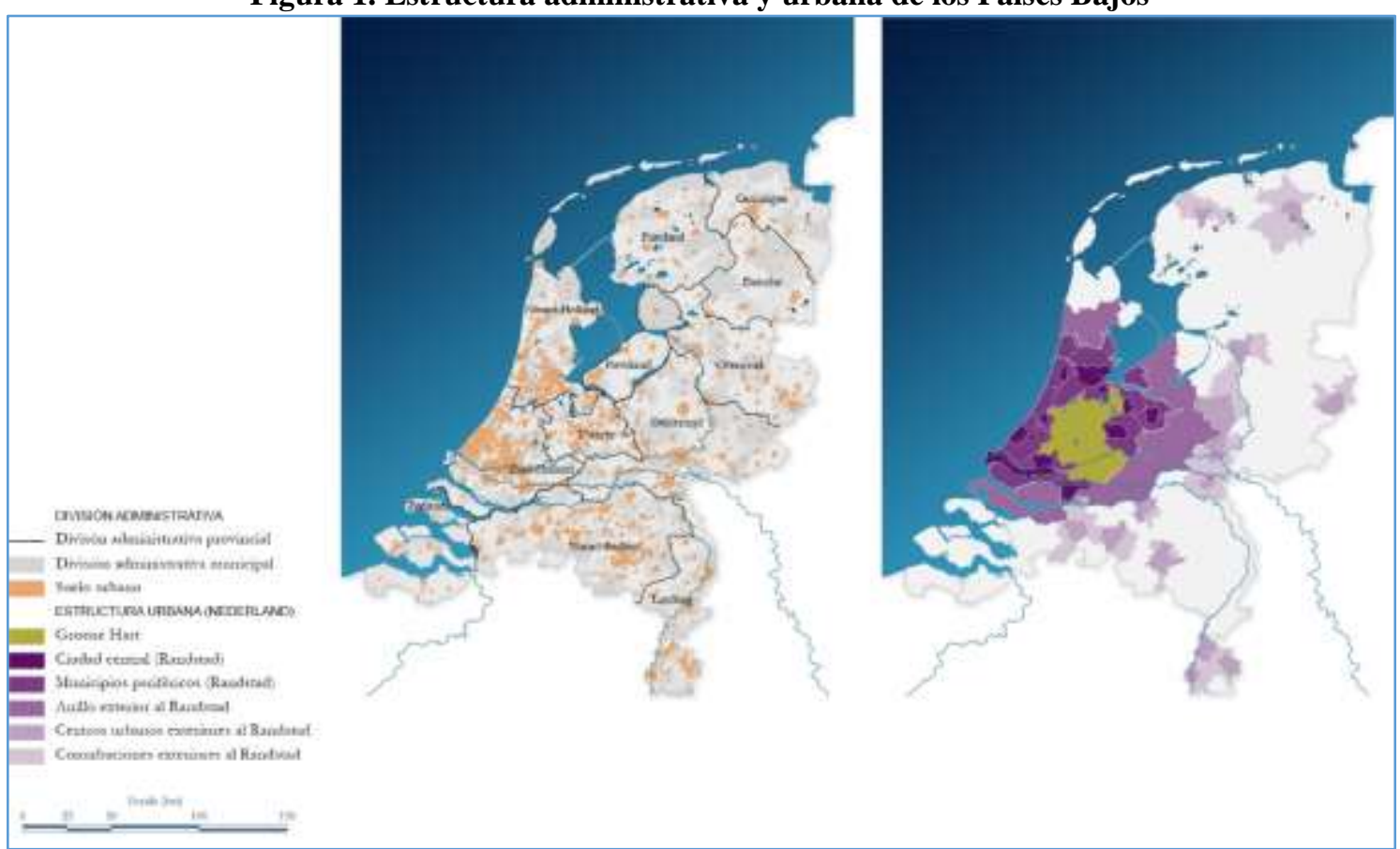

División administrativa de los Países Bajos de acuerdo con los límites provinciales y municipales (margen izquierdo), y estructura urbana en relación a la aglomeración del Randstad-Holland (margen derecho).

Fuente: Elaboración propia.

Actualmente, el Randstad-Holland ocupa una extensión de aproximadamente $6.000 \mathrm{~km}^{2}$, asimilable al tamaño del Great London o del Grand Paris, y se caracteriza por su elevada densidad, 1.200 habitantes por kilómetro cuadrado, y el carácter policéntrico, tanto físico como funcional, de su estructura urbana. La jerarquía urbana del Randstad-Holland está

\footnotetext{
${ }^{1}$ Filarski, 2008, p. 78.

${ }^{2}$ Dings, 2009, p. 11.
} 
encabezada por las cuatro grandes capitales: Ámsterdam, Róterdam, La Haya y Utrecht; que en ningún caso superan el millón de habitantes, seguidas de un segundo rango de ciudades medias con una población superior a los 100.000 habitantes: Haarlem, Leiden, Delft o Dordrecht. El Randstad-Holland es por lo tanto, una constelación de centros urbanos de diferente magnitud y especializados, a escala regional e internacional, ordenados en torno a un vacío agrícola de gran valor ecológico (figura 2). Esta conurbación ha presentado tradicionalmente un contraste físico-espacial muy acentuado entre usos urbanos y rurales. Sin embargo, la terciarización de la economía neerlandesa, durante el último cuarto de siglo, ha transformado la estructura espacial de la metrópolis del delta ${ }^{3}$. Los centros económicos, tradicionalmente ubicados en las grandes capitales, aparecen ahora diseminados por todo el territorio, con preferencia por los parques logísticos y los accesos a las redes viaria, ferroviaria y acuática. En este contexto, la red de transporte juega un papel clave en la construcción de la metrópolis, con una doble vocación: como instrumento de cohesión socioeconómica a escala regional y de integración en la red urbana europea a escala internacional.

Figura 2. Mapa toponímico del Randstad-Holland

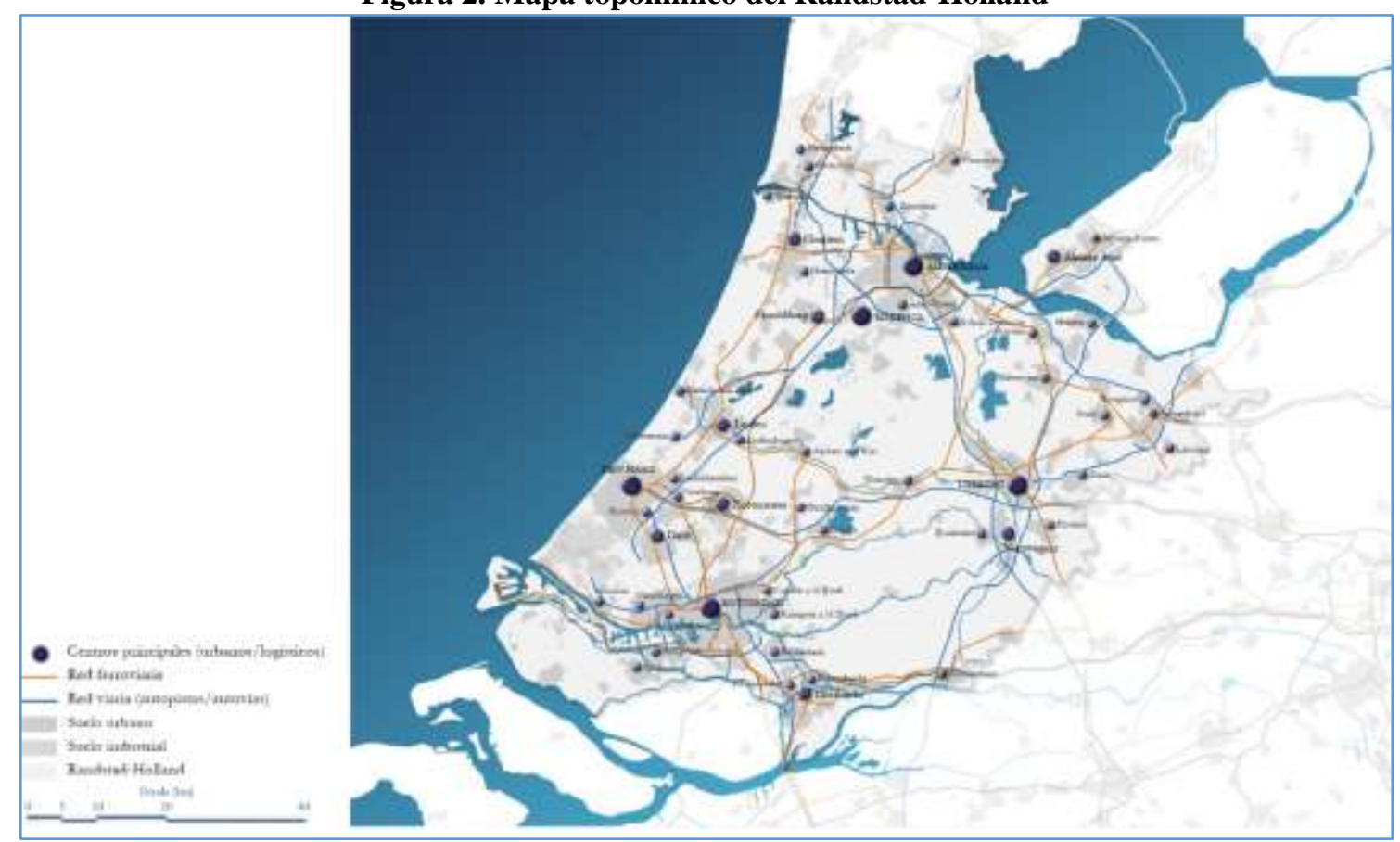

Superposición de las redes de transporte de altas prestaciones viarias y ferroviarias con la estructura jerárquica de centros urbanos y logísticos.

Fuente: Elaboración propia.

Las nuevas centralidades metropolitanas neerlandesas son espacios donde se ponen de manifiesto las relaciones de interdependencia entre movimiento y actividad. Estos centros participan de una triple dimensión metropolitana: morfológica, como metrópolis habitable; socio-económica, como metrópolis activa; y móvil, como metrópolis conectada. La distribución de estos nuevos enclaves por el territorio metropolitano supone una actualización del tradicional sistema urbano policéntrico, pero apoyado en los nodos de la red de transporte

\footnotetext{
${ }^{3}$ Este proceso de cambio en la economía neerlandesa se pone de manifiesto en las estadísticas ocupacionales de la ciudad de Ámsterdam: en 1950, el 40 por ciento de los empleos de la ciudad estaban vinculados al sector industrial, mientras que a finales de los 80 , este porcentaje había descendido hasta el 14 por ciento. En la actualidad, y según los datos publicados por el Ayuntamiento de Ámsterdam, sólo el 3,5 por ciento de los empleos pertenecen al sector secundario, porcentaje que asciende al 6,1por ciento en la Metropoolregio Amsterdam. Bureau Onderzoek en Statistiek, Gemeente Amsterdam, 2015.
} 
y los centros urbanos. La condición de nodo de la red dependerá por lo tanto, de la capacidad de integrar medios y escalas de movimiento diverso ${ }^{4}$, mientras que la condición de centro urbano, estará subordinada a la capacidad de propiciar la interacción entre individuos.

Desde un punto de vista metodológico, la integración de la movilidad y la planificación espacial se basa en aspectos cuantitativos vinculados a la densidad urbana, como son la intensidad de tráfico y el grado de actividad humana; y aspectos cualitativos relacionados con la mixtura de usos y grupos sociales, como la diversidad de medios urbanos y medios de transporte. Teniendo en cuenta parámetros cualitativos y cuantitativos se produce una actualización del modelo policéntrico urbano del Randstad-Holland basada en la planificación integrada de la movilidad y los usos del suelo, permitiendo además, el desarrollo de estructuras locales conectadas a escala regional y global.

El presente artículo está subdividido en dos apartados: el primero titulado "la Metrópolis del delta" hace una revisión al tratamiento que las figuras de planeación territorial han dado al modelo de ordenación policéntrico del Randstad-Holland en las últimas décadas. El capítulo comienza con la Declaración de la Deltametrópolis que oficializa la crisis del modelo territorial entre los corredores urbanos de las provincias periféricas y los centros urbanos tradicionales del oeste. Seguidamente se hace una revisión del IV y V Memorándum nacional que suponen un cambio de paradigma en las políticas de integración de la movilidad y los usos del suelo que ha perdurado hasta nuestros días en programas como la Stedenbaan o los Sleutelprojecten. En este contexto, aparece la figura del corredor nodal que vincula centralidad urbana y red de transporte. En el segundo apartado se realiza un análisis temático del territorio del Randstad-Holland desde una triple visión: como metrópolis habitable, metrópolis activa y metrópolis conectada, en base a parámetros cuantitativos y cualitativos, que finalmente, permitan poner en evidencia las oportunidades y debilidades del sistema urbano neerlandés.

\section{La Metrópolis del delta}

\section{La declaración de la Deltametrópolis: cambio de paradigma}

En pleno debate sobre la revisión de la IV Nota [IV Memorándum sobre ordenación espacial], los concejales de urbanismo de las cuatro principales capitales del Randstad-Holland: Ámsterdam, Róterdam, La Haya y Utrecht; firman la Verklaring Deltametropool [Declaración de la Metrópolis del delta] $]^{5}$. Esta iniciativa tiene como objetivo reivindicar el papel de los centros urbanos tradicionales del oeste neerlandés como motores económicos del país frente al auge de los corredores del transporte periféricos ${ }^{6}$ del Gelderland y Noord-Brabant ${ }^{7}$. La Declaración de la Deltametrópolis pone en evidencia dos conflictos persistentes en el

\footnotetext{
${ }^{4}$ Veldhuis, 2009, p. 13.

${ }^{5}$ VROM, 2002, p. 5.

${ }^{6}$ Zandbelt, 2012, p. 15.

7 En marzo de 1998, se funda la Berstuurlijke Commissie Randstad BCR [Comisión administrativa del Randstad]. Esta comisión depende del Ministerie van Volkshuisvesting, Ruimtelijke Ordening en Milieubeheer VROM [Ministerio de vivienda, ordenación espacial y medio ambiente] y su objetivo es promover la cooperación entre administraciones locales, provinciales y nacionales en el Randstad-Holland, en aspectos vinculados con las infraestructuras, la vivienda y el medio ambiente. Entre los organismos implicados se encuentran: los Ministerios V\&W, VROM, LNV, EZ y BIZA; las provincias de Noord-Holland, Zuid-Holland, Utrecht y Flevoland; organismos regionales como: ROA (Ámsterdam), Stadsregio Róterdam, Bestuur Regio Utrecht y Haaglanden; además de las cuatro capitales anteriormente citadas.
} 
planeamiento urbanístico neerlandés prácticamente desde sus orígenes: por una parte, la divergencia entre las escalas de planificación y gestión, y por otra, la necesidad de actualizar un modelo urbano de naturaleza policéntrica ${ }^{8}$, comprometido por el proceso de integración europea. De este modo, la Verklaring Deltametropool tiene como finalidad última la refundación del Randstad-Holland a partir del fortalecimiento de los centros urbanos y de los conectores de transporte.

Las autoridades firmantes optan por denominar a esta nueva realidad territorial como la Deltametrópolis, en sustitución de la denominación tradicional: Randstad. El RandstadHolland es un concepto con connotaciones morfológicas, profundamente arraigado en el imaginario popular neerlandés. Según la tradición, Albert Plesman, cofundador de la Koninklijke Luchtvaar Maatschappij KLM [Real Compañía de transporte aéreo], acuña el término en 1930 durante un vuelo de exploración por el oeste neerlandés en busca del emplazamiento adecuado para el aeropuerto corporativo: el futuro Ámsterdam-Schiphol. Plesman advierte la existencia de una cadena de centros urbanos de extensión variable dispuestos en forma de herradura en torno a un vacío central de uso preferentemente agrícola: el Groene Hart ${ }^{9}$.

En el Randstad-Holland, el anillo urbano y el vacío interior forman una unidad interdependiente desde el punto de vista morfológico y funcional y las propuestas de ordenación territorial han estado tradicionalmente orientadas a la contención del desarrollo urbano de los asentamientos, como a la protección del vacío agrícola. Sin embargo, el concepto Deltametrópolis hace referencia a un sector geográfico más amplio: el delta neerlandés, y vincula dos de las aspiraciones históricas de este territorio: en primer lugar, la condición de metrópolis integrada en la red urbana europea ${ }^{10}$, y en segundo lugar el vínculo histórico de la sociedad neerlandesa con el agua, como instrumento destinado a garantizar la calidad ambiental. La delimitación física de la metrópolis ha sido históricamente una cuestión polémica y es necesario referenciarla a un ámbito territorial superior: las Westen des Lands [Tierras del oeste] y por extensión al resto del país. En este sentido, cuanto mayor es el desequilibrio demográfico y económico entre el oeste y las provincias periféricas, más precisa es la delimitación de la metrópolis en los planes de ordenación territorial.

La Declaración define la Deltametrópolis como una ciudad cohesionada, dinámica, contenida y bien administrada. Una realidad urbana única compuesta por áreas urbanas y naturales diversas cuya cohesión se basa en una sofisticada red de transporte. Esta definición se opone a la ciudad fragmentada en que se ha convertido en Randstad-Holland, formada por un mosaico de asentamientos humanos de dimensión diversa y redes infraestructurales. En palabras de Peter Hall, el valor de este territorio frente a otras aglomeraciones urbanas es precisamente, la calidad de su policentrismo ${ }^{11}$. En el Randstad-Holland, las funciones urbanas tradicionales

\footnotetext{
${ }^{8}$ Hall, 2006, p. 145.

${ }^{9}$ No obstante, esta estructura territorial ya había sido identificada por Th. K.van Luhuizen durante el I Congreso de la International Federation for Town and Country Planning and Garden Cities, celebrada en Ámsterdam en 1924. Los asistentes al congreso acuerdan, entre otros aspectos, la necesidad de una escala regional de ordenación espacial y la preservación de los espacios abiertos de gran escala, principios aplicables tanto al Randstad-Holland como al Groene Hart.

${ }^{10}$ VROM, 2008, p. 45.

${ }^{11}$ Descrito como: Schiphol airport, in fact, lies in the centre of one of the most extraordinary urban regions of the world. All around is the polder landscape of the provinces of North and South Holland, which has always dominated the nation of which it forms a part; (...). Today (1966) the cities and towns of Holland have grown so close together that they form, in an important sense, one city, though a city of a particular form. The Dutch call
} 
como son la administración, la educación o la cultura, no se emplazan en un único centro sino que se encuentran diseminadas por el territorio pero a distancias relativamente próximas. ${ }^{12} \mathrm{En}$ este sentido, la Declaración propone la transición de la ciudad fragmentada a la cohesionada a partir de la actuación sobre cuatro componentes físicos del sistema: el agua, el paisaje, los espacios urbanos de interacción y la red de conexiones.

Figura 3. Localización del Aeropuerto Internacional de Ámsterdam-Schiphol

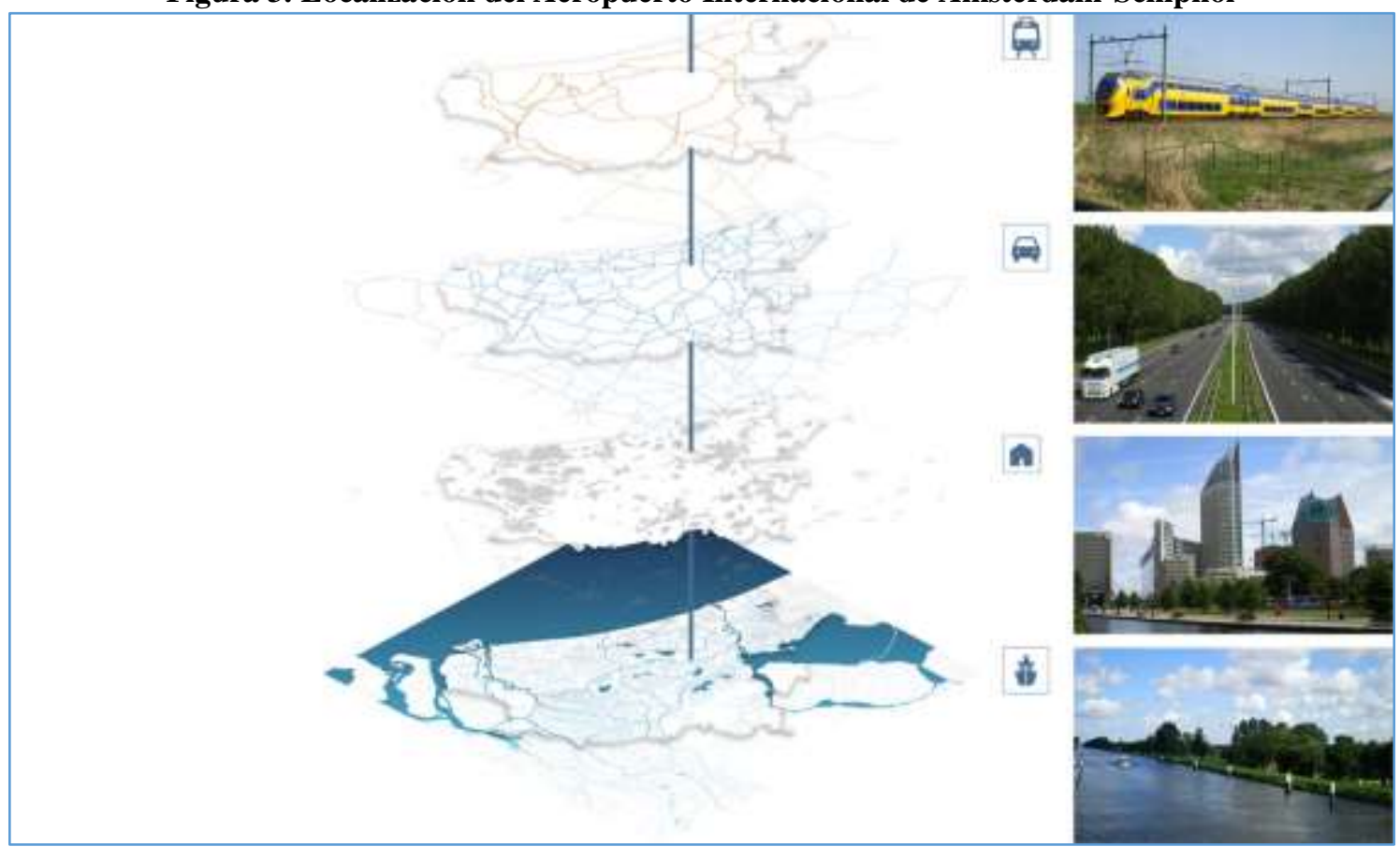

Ubicación del principal nodo económico y de transporte del Randstad-Holland (AA-Schiphol) en relación a la red ferroviaria, viaria, urbana y acuática.

Fuente: Elaboración propia.

El contenido de la Declaración se estructura en veintiún artículos orientados a la mejora de la competitividad internacional de las capitales históricas y al establecimiento de unas estrategias de consenso que promuevan la cohesión interna de la región. El elemento clave en la articulación de la metrópolis es la red de transporte. La Verklaring Deltametropool aboga por la multiplicación de las conexiones entre los sistemas viario y ferroviario, y la promoción del transporte público por carretera, como alternativa al uso masivo del vehículo privado. La consolidación de actividad urbana en los centros de intercambio modal como estaciones ferroviarias, accesos a la red viaria, puertos y aeropuertos; dibujan una nueva estructura nodal a escala metropolitana que integra también los centros urbanos tradicionales. En definitiva, un nuevo orden territorial basado en la complementariedad entre nodos de transporte y nodos urbanos, una red de comunicación eficiente y unas puertas metropolitanas: el Aeropuerto Internacional de Schiphol (figura 3) y el Puerto de Róterdam que pongan en relación la red global y la local.

it Randstad Holland: the ring city. It has the shape of a great horseshoe, pointing with its open end towards the south-east (...). And in the centre of the horseshoe, there is still a vast tract of open rural land.

Hall, 1966, p. 88-89.

12 Blank, 2009, p. 23. 


\section{Antecedentes. La institucionalización del policentrismo urbano, IV Nota (1988-1991)}

Los primeros planes de ordenación nacional o Notas, aprobados tras la Segunda Guerra Mundial, centran sus esfuerzos en la recuperación socio-económica y modernización del país ${ }^{13}$. Las estrategias llevadas a cabo desde la planificación urbana para la recuperación son: la gestión del crecimiento demográfico, la distribución equilibrada de la actividad en el territorio y el desarrollo y mejora de la red de transporte. En estos Memorándums las políticas sociales se consideran prioritarias frente a las políticas económicas, de acuerdo con el principio: la economía se beneficia del progreso social. En este sentido, el IV Memorándum supone un cambio de rumbo en los planes nacionales de ordenación puesto que confía en el fortalecimiento económico como estrategia para el desarrollo social. En este sentido, la $I V$ Nota $^{14}$ se plantea como un documento abierto, alejado del carácter finalista de sus predecesoras, basado en los principios de urbanidad y compacidad.

Los objetivos de la IV Nota son la promoción del desarrollo económico y la consolidación internacional de los centros urbanos neerlandeses, en un contexto de integración europea y terciarización económica ${ }^{15}$. Las estrategias trazadas para la mejora de la competitividad del país pasan necesariamente por la incorporación de criterios de calidad ambiental, de acuerdo con la nueva conciencia ecológica. En este sentido, la IV Nota apuesta por la densificación urbana selectiva, la renovación y equipamiento de los centros urbanos, la promoción de los sistemas públicos de transporte, para combatir el creciente uso del vehículo privado y, finalmente, la integración de la ordenación territorial y la movilidad con el objetivo de garantizar la proximidad de los centros de residencia, trabajo y recreo.

En este contexto, las grandes capitales del Randstad-Holland cobran protagonismo. La IV Nota incide en el desarrollo de los centros urbanos tradicionales con el propósito de situarlos en la vanguardia europea. El documento esboza un nuevo orden jerárquico y funcional para la red urbana neerlandesa. La categoría de cada uno de los centros dependerá del grado de conexión, a escala local y global, con las redes económicas, culturales y de transporte. En definitiva, la IV Nota propone la actualización de la estructura policéntrica neerlandesa mediante la promoción de los núcleos urbanos tradicionales, especialmente las capitales del Randstad-Holland, y los puertos logísticos ${ }^{16}$. En el marco de este nuevo sistema nodal, la $I V$ Nota prioriza el desarrollo de los principales accesos o Mainports ${ }^{17}$ : el aeropuerto de

\footnotetext{
${ }^{13}$ Wagenaar, 2011, p. 502.

${ }^{14}$ VROM, 1988, p. 12.

${ }^{15}$ La caída del muro de Berlín (1989), el desmembramiento de la Unión Soviética y la apertura de las fronteras en el marco del libre comercio de la Unión Europea (1992) anticipan una nueva estructura político-urbana a escala continental. Los Países Bajos se postulan como centro logístico, favorecidos por su localización geográfica, en el centro de la nueva red de flujos del continente.

${ }^{16}$ Los cuatro principales centros urbanos del Randstad-Holland: Ámsterdam, Róterdam, La Haya y Utrecht, pese a su elevado nivel de especialización funcional, a escala internacional, se consideran poco competitivos respecto a otras conurbaciones próximas. En este sentido, algunos planificadores urbanos apuestan por considerar a Ámsterdam como el único centro urbano con proyección internacional de la región y situar a la capital neerlandesa a la altura de otros centros como París o Londres. Las consecuencias de esta reestructuración de la jerarquía urbana neerlandesa implican la degradación de Utrecht hasta liderar el rango de ciudades medias. Una década más tarde, la estrategia se basará en la subdivisión del Randstad-Holland en dos subsistemas urbanos en competencia: el Ala sur (Sistema Róterdam-La Haya), y el Ala norte (Sistema Ámsterdam-Utrecht).

${ }^{17}$ Los puertos son los motores económicos del país. Los planes de ordenación territorial dedican una especial atención a la promoción y el desarrollo del Puerto de Róterdam y el Aeropuerto de Schiphol, tanto en la mejora de las conexiones internacionales como en el fomento de las sinergias económicas con los centros productivos a escala local. De acuerdo con los objetivos del Memorándum, el desarrollo de los puertos se diseña además, teniendo en cuenta la preservación de los valores ecológicos del medio.
} 
Ámsterdam-Schiphol y el Puerto de Róterdam, e identifica 13 subcentros distribuidos por todo el territorio nacional: las Stedelijke Knoppunten ${ }^{18}$ [encrucijadas urbanas], y 17 Stadsgewesten [regiones urbanas]. Las Stedelijke Knoppunten reciben un trato preferente en la definición de la estructura espacial al desempeñar un papel como hubs regionales con un elevado nivel de equipamiento urbano, y conectadas con las redes locales e internacionales. Simultáneamente, las Stadsgewesten están organizadas como entidades autónomas con servicios acordes a su dimensión, para evitar la saturación de las infraestructuras del Randstad-Holland.

Además de la consolidación de una estructura urbana altamente jerarquizada, la $I V$ Nota promueve la optimización del servicio de transporte público y el fomento de medios de locomoción no motorizados, como estrategia para la reducción del uso del vehículo privado que satura la red viaria. La crisis del petróleo que había afectado de forma especial a los Países Bajos, supone un cambio en las políticas energéticas gubernamentales en favor de medios de transporte menos dependientes de los combustibles fósiles. De este modo, en la década de los 80, surge un interés renovado por el ferrocarril. Medidas encaminadas a la mejora de la gestión como la ampliación de la frecuencia de paso, la mejora de las conexiones y los proyectos de renovación de las principales estaciones ${ }^{19}$, contribuyen a la modernización del sistema ferroviario neerlandés. Las terminales de transporte se convierten en grandes centros multifuncionales que integran actividades tradicionalmente vinculadas a la ciudad central, de acuerdo con las nuevas políticas de compactación urbana. ${ }^{20}$ En este contexto, se desarrollan el primer programa de Sleutelprojecten [proyectos clave] ${ }^{21}$ en el entorno de las estaciones centrales, que suponen la primera incursión de la Administración nacional en la gestión del proyecto urbano local.

En 1991 se aprueba la IV Nota over de ruimtelijke ordening Extra VINEX [IV Memorándum de ordenación espacial extra] ${ }^{22}$ que desarrolla los objetivos de la IV Nota en materia de vivienda. Las nuevas políticas de localización de actividad en el territorio se basan en la reducción de la movilidad obligada en medios motorizados mediante la distribución selectiva de los nuevos centros, tanto productivos como residenciales. Cada empresa genera un tipo de movilidad en función del número de empleados-clientes, y a la forma de transporte de mercancías. Las medidas, recogidas en el programa de $A B C$-locaties [Localizaciones $\mathrm{ABC}$, van acompañadas de disposiciones restrictivas respecto del uso del vehículo privado y penalizan aquellos sectores no accesibles en transporte público. Además, el plan fomenta el intercambio modal entre las diferentes redes de transporte: ferrocarril, tranvía, metro y autobús, así como la conexión a las redes de transporte no motorizadas. Los planes de renovación urbana en el entorno de las estaciones ferroviarias tanto centrales como suburbanas, ocuparán parte de las inversiones públicas en adelante.

\footnotetext{
${ }^{18}$ Las encrucijadas urbanas son el elemento clave de la política de compactación urbana. El objetivo es favorecer la implantación de actividad en determinados centros con unos niveles de densidad cuantitativa y mixtura de funciones suficientes para asegurar la competitividad de estos núcleos urbanos. Las administraciones públicas priorizan la inversión en equipamiento e infraestructura de estos nodos, no como estructuras aisladas, sino integrados en las redes locales, regionales y nacionales.

${ }^{19}$ Bouwer, 2010, p. 22.

${ }^{20}$ Boeijenga, 2011, p. 24.

${ }^{21}$ VROM, 1991, p. 45.

${ }^{22}$ VROM, 1994, p. 5.
} 


\section{La polémica: el corredor urbano, V Nota (2001)}

En 1999, se publica De ruimte van Nederland: Startnota Ruimtelijke Ordening [El espacio de los Países Bajos: Memorándum inicial de ordenación espacial], como informe preliminar de la V Nota. Este estudio propone un modelo de desarrollo basado en un elemento hasta la fecha excluido del planeamiento urbanístico neerlandés: el corredor urbano ${ }^{23}$. Aunque los planes de escala supralocal habían evitado deliberadamente esta forma de ordenación, las administraciones locales promueven la implantación de actividad productiva en los márgenes de la red de transporte y en particular en los accesos a la red de autopistas. La Startnota, como instrumento de debate, distingue entre dos escalas de diseño del continuo o cinta urbana: la global y la regional ${ }^{24}$. El concepto de corredor urbano se debate desde una doble vertiente: la económica y la espacial. La falta de consenso entre los agentes involucrados en la redacción de la V Nota deriva en la sustitución del concepto de corredor por el de red urbana, desde una óptica espacial, sin embargo, el ministerio de economía incorpora el concepto de corredor económico al programa de gobierno.

Cabe tener en cuenta que la dependencia de la red de transporte es común a ambas dimensiones: la económica y la espacial. La saturación del sistema viario y ferroviario fuerzan la adopción de soluciones de integración entre ordenación espacial y movilidad, tal y como se recogía en la Visie op verstedelijking en mobiliteit [Visión de la urbanización y de la movilidad] publicada en 1995. En este sentido, los nodos de intercambio modal entre la red viaria, ferroviaria y acuática centran el interés del planeamiento territorial como localizaciones óptimas para el establecimiento tanto de actividad productiva como de usos residenciales. Ahora bien, el nodo intermodal no es un elemento aislado en la red sino que la sucesión de nodos a lo largo de los ejes del transporte configura una estructura jerarquizada comúnmente aceptada: el corredor multinodal ${ }^{25}$. Esta figura de ordenación espacial, compatible con el discurso de compacidad y alejada del concepto de cinta urbana continua e integra, además, la red económica, ecológica y de transporte público.

Finalmente, en pleno debate sobre el concepto de corredor urbano y corredor multimodal, se publica en 2001 la V Nota over de ruimtelijke ordening in de Nederland bajo el lema: decentraal wat kan, centraal wat moet [Descentraliza donde sea posible, centraliza donde sea necesario $]^{26}$. Este documento no rehúye los temas clave que habían centrado el debate en

\footnotetext{
${ }^{23}$ El corredor es un instrumento habitual en el análisis de las dinámicas económicas y de la movilidad neerlandesa. Sin embargo, este instrumento, con evidentes implicaciones morfológicas, no tiene una traducción directa en las políticas de ordenación espacial y ha quedado sistemáticamente excluido de los diversos planes de ordenación territorial. En la actualidad, el concepto de corredor ha sido asumido por el Ministerie van Economische Zaken, Landbouw en Innovatie y por las Cámaras de Comercio como estrategia de planificación de las dinámicas económicas: "Los corredores son ejes de desarrollo económico que discurren a lo largo de la infraestructura. Su desarrollo se percibe como un proceso natural, una expresión de la preferencia de localización de las empresas. Son espacios accesibles y con disponibilidad de suelo para el crecimiento". Duinen, 2004, p. 178 .

${ }^{24}$ Las tres escalas de ordenación territorial están vinculadas a las tres dimensiones del concepto de corredor: la escala internacional en relación al corredor como eje del transporte, la escala regional vinculada al concepto de eje económico y finalmente, la escala local, relacionada con el concepto de eje de urbanización. Duinen, 2004, p. 178.

${ }^{25}$ A escala regional, las provincias del sur y del este reivindican la promoción de sus corredores del transporte. El objetivo es la mejora de las conexiones de estos territorios, en la periferia del Randstad-Holland, a la red nacional e internacional del transporte.

${ }^{26}$ Finalmente, la V Nota no es aceptada por el Parlamento neerlandés. En 2006, se actualiza el Memorándum con un nuevo documento complementario: la Nota ruimte que recoge algunos de los principios presentados previamente como el de: decentraal wat kan, centraal wat moet.
} 
materia de planificación espacial en las últimas décadas en los Países Bajos pero su rechazo pone de manifiesto la falta de consenso sobre el modelo de desarrollo urbano entre los diferentes agentes con competencia en esta materia. Los objetivos de la V Nota son: la intensificación de las áreas urbanas, actualizando la política de las $A B C$-locaties; la mixtura de usos como apoyo al desarrollo de nueva actividad económica; la modernización de las redes infraestructurales, en particular las que confluyen en las principales puertas territoriales; y la mejora de la calidad e identidad del medio natural, intensificando el contraste entre medio urbano y rural. La aproximación a la ordenación territorial se realiza mediante métodos de estratificación funcional: el medio físico o sustrato primario, sobre el cual se ordenan el resto; los patrones de colonización humana o sustrato de ocupación; y, finalmente, las redes infraestructurales o sustrato de la red $^{27}$.

Uno de los aspectos más polémicos de la $V$ Nota consiste en la definición de un mapa bicolor de contornos: rojo para el medio urbano y verde para el medio natural, en sustitución del mapa de usos del suelo de la IV Nota. El objetivo de esta nueva política de contornos es la restricción de la urbanización en el delta para evitar tanto los procesos de dispersión urbana como el desarrollo de cintas urbanizadas a lo largo de las redes de transporte terrestre. Esta estrategia se coordina con diversos planes de restauración de las conexiones ecológicas en el Randstad-Holland. Los contornos verdes, competencia de las administraciones nacional y provincial, definen los sectores de interés de la red ecológica y cultural (sustrato primario). El objetivo de esta delimitación es garantizar la preservación de sus valores especiales ${ }^{28}$. Los contornos rojos (sustrato urbano), competencia de las administraciones locales, definen áreas urbanas consolidadas o ámbitos de desarrollo, supervisados por las autoridades provinciales. El objetivo del contorno rojo es delimitar los ámbitos susceptibles de acoger nuevos crecimientos residenciales o productivos, incluyendo la transformación de sectores obsoletos. La definición de estos límites se consensua entre los municipios afectados y es coordinada por la administración provincial, de acuerdo con las previsiones de demanda prevista en la $V$ Nota. La polémica sobre la delimitación del contorno urbano, bajo la sospecha de ser instrumento de planificación al servicio de intereses particulares locales, es uno de los detonantes de la no aprobación del V Memorándum ${ }^{29}$.

\footnotetext{
${ }^{27}$ Este Memorándum no especifica actuaciones en lugares concretos sino que establece el marco conceptual para el desarrollo de las futuras políticas de desarrollo territorial.

${ }^{28}$ Entre los sectores incluidos se encuentran: los paisajes nacionales, las áreas de patrimonio de la humanidad, la National Ecological Infrastructure y espacios protegidos a escala internacional por las directivas EU Bird y Habitat de la UE. Además son susceptibles de incorporarse el Randstad green structure, las Belvedere-locations y los national buffers. Los paisajes nacionales, como figura de ordenación territorial incluyen tanto medios urbanos como naturales de interés nacional, el Groene Hart en el Randstad-Holland es uno de ellos.

${ }^{29}$ En el interior del límite urbano (rojo) se definen hasta seis tipos de medios de carácter residencial - laboral, que a su vez determinan diferentes estrategias de intervención:

Ciudades centrales, (centros históricos y distritos ferroviarios). La estrategia consiste en incrementar la densidad de estos sectores de acuerdo con un plan de ordenación que favorezca la mixtura de actividad.

Ciudades periféricas, (distritos urbanos y ciudades jardín previos a los 40). Sectores susceptibles de transformación bien como inner cities o como green cities. Implementar nuevas actividades para evitar convertirlos en ciudad-dormitorio, atendiendo a sus valores de identidad y la escala humana.

Verde urbano, (planes de extensión urbana, desarrollo de centros urbanos y áreas rurales actuales); Villas (centros históricos y nuevos centros); y Centros rurales (villas residenciales aisladas en entornos de alto valor paisajísticos). Para estos tres tipos hay una gran demanda de vivienda. La residencia en medios rurales debe restringirse a los núcleos rurales actuales (de baja densidad) o a la creación de nuevas ciudades de baja densidad. Mixtura de usos evitando el carácter exclusivamente residencial.

Centros productivos, (enclaves laborales con residencia). Favorecer la diversidad vertical de usos y prestar especial atención a los espacios colectivos de relación. La definición de nuevos enclaves laborales debe coordinarse a escala regional.
} 
La $V$ Nota, pese a no llegar a aprobarse, recoge el concepto de red urbana clave en el futuro desarrollo del delta neerlandés. La red urbana se define como instrumento para la integración y promoción del sistema urbano neerlandés, constituido por núcleos urbanos compactos altamente especializados y conectados. El desarrollo de la red urbana pasa por el acuerdo entre los programas de usos del suelo y el sistema de transporte, a escala municipal, provincial y nacional. Por otra parte, a escala local se promueve el desarrollo de centros de actividad en las proximidades de los nodos del transporte. Estas nuevas centralidades urbanas se coordinan a escala provincial con el objetivo de impulsar la complementariedad en lugar de la competencia entre ellos. En el marco de esta estrategia se proyecta una segunda generación de Sleutelprojecten vinculados a las grandcs estaciones ferroviarias nacionales y se implementan programas regionales relacionados con la red tranviaria como por ejemplo el Stedenbaan [Ciudades en la vía], que se describe a continuación.

\section{El Programa Stedenbaan}

\section{Vertebración territorial a partir de la red de transporte público}

La movilidad derivada de los crecimientos de baja densidad en la periferia de las grandes capitales como Ámsterdam o La Haya, repercute en el incremento de la movilidad tanto en la red viaria neerlandesa, a causa del uso generalizado del vehículo privado, como en la red ferroviaria, puesto que las estaciones suburbanas infrautilizadas afectan la eficiencia del servicio. En pleno proceso de dispersión urbana, el transporte público en general y el sistema ferroviario en particular pierden su papel tradicional como agentes estructuradores de la movilidad metropolitana en favor del vehículo privado. Con el objetivo de restaurar este papel, el Gobierno neerlandés propone la integración de las políticas de movilidad, basadas en la promoción del transporte público, y de ordenación espacial, basadas en el modelo de ciudad $\operatorname{compacta}^{30}$. Esta estrategia debería además, frenar los procesos de deslocalización de la actividad productiva que priorizan la proximidad a la red viaria frente a la ferroviaria.

La red de transporte de altas prestaciones, en cualquiera de sus modalidades, y la red urbana no se han desarrollado de forma paralela en el delta neerlandés. En este sentido, la red de centros urbanos se ven forzados a establecer nuevas relaciones de interdependencia con la red de nodos logísticos o de transporte. El planeamiento territorial no es ajeno al desacuerdo existente entre ambas redes y a partir de la década de los 90 las Administraciones públicas ponen en marcha varios programas de coordinación de la movilidad y los usos del suelo a escala regional, provincial y nacional. Esta estrategia de coordinación se anticipa en las políticas de localización ABC de la IV Nota y IV Nota Extra (VROM), y en documentos de carácter sectorial como el Programma Hoogfrequent Spoorvervoer PHS [Programa de alta frecuencia del servicio ferroviario] (ML\&V). La visión integrada de movilidad y ordenación espacial es por lo tanto transversal, compete a organismos públicos y privados; y multiescalar, comprende desde el nodo local a la región urbana.

Este tipo de planes y programas están enmarcados en la transición de los modelos de ordenación espacial desde el monocentrismo jerárquico hacia redes policéntricas más homogéneas ${ }^{31}$. Esta transformación supone el fortalecimiento de la red de conexiones entre centros y la creación de nuevas estrategias de cooperación que permitan coordinar el crecimiento económico de la región. El referente conceptual de estos nuevos programas se

\footnotetext{
${ }^{30}$ Boelens, 2011, p. 11.

${ }^{31}$ Balz, 2009, p. 75.
} 
encuentra en los programas Transit Oriented Development TOD $^{32}$ estadounidenses o las Transport Development Areas TDA británicas. El objetivo de estos planes es el aprovechamiento del área de acceso a las redes de transporte público, de acuerdo con criterios de mixtura funcional, intercambio modal y calidad medioambiental. El caso neerlandés sin embargo, presenta particularidades relacionadas con la escala de proyectación y la gestión público-privada.

\section{Stedenbaan (Zuid Holland)}

El ámbito de implantación del programa Stedenbaan ${ }^{33}$ es el Zuidvleugel [Ala sur] del Randstad-Holland. Este territorio está habitado por 3,5 millones de personas y emplea a 1,5 millones de trabajadores. La estructura urbana del Zuidvleugel es marcadamente policéntrica pero dos núcleos destacan demográficamente sobre el resto: Róterdam y La Haya ${ }^{34}$. El sistema se completa con un segundo rango de ciudades entre las que se encuentran, por orden decreciente de población: Zoetermeer, Leiden, Dordrecht, Westland y Delft. La eficiencia de la red de transporte en regiones urbanas policéntricas depende de la gestión integrada de los tráficos transnacional, regional y local. La yuxtaposición de la red viaria y ferroviaria en el Zuidvleugel favorece la coordinación de la movilidad regional.

La pérdida de competitividad internacional afecta de forma particular a la provincia de Zuid Holland [Holanda Meridional], especialmente durante la primera década del siglo XXI, puesto que gran parte de la economía de la provinvia depende del Puerto de Róterdam y este pierde posiciones frente a sus competidores asiáticos. En este contexto socio-económico, se pone en marcha el programa Stedenbaan $(2003)^{35}$, promovido por la Bestuurlijk Platform Zuidvleugel [Plataforma administrativa del Ala sur] en colaboración con administraciones de escala regional y local, así como la compañía Nederlandse Spoorwegen NS [Compañía ferroviaria nacional] y empresas semipúblicas de ámbito suprarregional. En 2005, el gobierno provincial de Zuid-Holland crea el Atelier Zuidvleugel [Estudio del Zuidvleugel] apoyado por los municipios de Róterdam y La Haya, el BPZ, el VROM y los programas de investigación Habiforum y Transumo.

El objetivo último del proyecto Stedenbaan es la integración de la red de Hoogwaardig Openbaar Vervoer HOV [Transporte público de calidad] y la Ruimtelijke Ordening RO [Ordenación espacial]. Con este propósito se plantean dos estrategias: en primer lugar la mejora de la eficiencia del servicio ferroviario y en segundo lugar, la gestión coordinada del desarrollo urbano en el entorno de las estaciones ferroviarias ${ }^{36}$. Los objetivos, sin embargo, no sólo se reducen a criterios cuantitativos tales como el incremento de la frecuencia de paso, la capacidad de los vehículos y la densidad urbana. La integración de HOV-RO, a escala

\footnotetext{
${ }^{32}$ Bertolini, 2009, p. 3

33 Atelier Zuidvleugel, 2007, p. 11.

${ }^{34}$ La ciudad de Róterdam dispone en 2015 de 623.956 habitantes, mientras que la población de la ciudad de La Haya, tercera en el ranking demográfico neerlandés, es de 515.739 habitantes en la misma fecha, según datos actualizados de los respectivos Ayuntamientos. Esto supone que ambos núcleos urbanos concentran un tercio de la población total de la provincia de Zuid-Holland.

${ }_{35}$ El proyecto se desarrolla a lo largo de las líneas ferroviarias existentes en el Zuidvleugel, en concreto en las rutas Schiphol - Dordrecht, La Haya - Gouda y Róterdam - Gouda. Este programa es posible, en parte, gracias a la puesta en servicio de la línea de alta velocidad HSL entre Ámsterdam y la frontera con Bélgica en 2009 que permite aumentar la capacidad de la red antigua: ampliando la frecuencia de los Intercity y Sprinters, de 4 a 6 vehículos por hora.

${ }^{36}$ Cavallo, 2011, p. 42.
} 
regional, implica la consideración de criterios cualitativos para la mejora de la competitividad internacional del Zuidvleugel. En definitiva, el programa Stedenbaan plantea un escenario de desarrollo económico en el Randstad-Holland basado en la integración de la red urbana y la red de transporte.

El proyecto comprende una triple dimensión: socio-económica, apuesta por la compacidad urbana como estrategia de mejora de la eficiencia de la red de transporte; administrativa, establece una relación transversal entre agentes y multiescalar en cuanto a la gestión institucional del plan; y finalmente científica, puesto que las estrategias propuestas se ensayan en modelos virtuales que permiten anticipar el desarrollo de la región. Pese a la ambición del programa, el Zuidvleugel no dispone de un marco jurídico o competencial que autorice la aprobación de planes de ordenación espacial, por este motivo, cualquier plan de escala supralocal responde al acuerdo voluntario entre organismos locales, coordinadas en todo caso por la administración provincial de Zuid-Holland.

\section{Estructura y escenarios}

De acuerdo con el Atelier Zuidvleugel, el programa está estructurado en tres fases: análisis de la capacidad de transformación física del sector, estudio de la potencialidad de desarrollo, y finalmente, evaluación de la eficiencia de cada proyecto y su contribución al cumplimiento de los objetivos para la región. A efectos prácticos, la primera fase se concreta en un catálogo de las transformaciones previstas en el entorno de las estaciones en el período 2010-2020, de acuerdo con el planeamiento local ${ }^{37}$. La segunda fase consiste en la elaboración de un inventario de estrategias de ordenación de acuerdo con las características espaciales de los distritos ferroviarios y las redes de transporte a lo largo de la red ${ }^{38}$. En total, de la interacción entre ordenación espacial y red de transporte resultan nueve estrategias de desarrollo o tipos de Stedenbaan, derivados del impacto de la movilidad en un determinado medio y viceversa. Son los siguientes:

- Área rural, sectores situados en medios agrícolas adecuados para el desarrollo de tejidos urbanos de baja densidad y usos recreativos.

- Villa, áreas residenciales situados en las proximidades de un núcleo rural con capacidad de convertirse en comunidades autónomas.

- Ámbito periurbano, regeneración y consolidación de sectores vacantes situados en la periferia de las grandes ciudades.

\footnotetext{
${ }^{37}$ El programa establece un ámbito de servicio en torno a la estación ferroviaria de 1.200 metros de radio, con independencia de las particularidades físicas de cada emplazamiento. Esta distancia es la recorrida por una bicicleta en un periodo de 10 minutos. Este ámbito aplicado al conjunto de todas las estaciones ferroviarias de la región supone una superficie de 18.000 hectáreas, un cuarto de toda la superficie urbanizada del Zuidvleugel. El 20 por ciento de esta superficie está pendiente de transformación en el periodo 2010-2020. La urbanización de este 20 por ciento de acuerdo con las densidades medias de la región supondría la construcción de más de 40.000 viviendas y un millón de metros cuadrados de usos terciarios.

${ }^{38}$ Los criterios de análisis, entre movilidad y usos del suelo, en esta segunda fase son: el grado de acceso en transporte público y privado, la densidad de vivienda y de empleo, y la diversidad de actividad. Estos criterios son evaluados en el entorno de 47 estaciones ferroviarias (34 existentes y 13 potenciales) pero el alcance de las actuaciones afecta a toda la región.
} 
- Ciudades del futuro, áreas urbanas de alta densidad y accesibles que pueden desarrollarse como áreas de actividad mixta con identidad.

- Centros de negocio, reconversión de polígonos industriales situados en los márgenes de la red viaria de altas prestaciones.

- Enclaves suprarregionales, áreas vinculadas a cruces de la red viaria principal, adecuadas para la localización de usos de escala nacional.

- Hubs en el Randstad-Holland, áreas de usos no intensivos pero accesibles en transporte público o privado para experimental la mixtura funcional.

- Ciudades creativas, áreas accesibles en cualquier medio de transporte, destinadas a albergar usos residenciales y centros laborales vinculados a la innovación.

- Centros urbanos, áreas accesibles en cualquier medio de transporte, a excepción del vehículo privado, planificadas de acuerdo con las necesidades de los usuarios del transporte público.

El desarrollo urbano y económico de estos corredores de transporte ferroviario se basa en la planificación coordinada de los diferentes nodos de acceso. El programa Stedenbaan propone tres posibles escenarios de especialización funcional en función de los tipos de desarrollo seleccionados en cada una de las estaciones: densificación, red y sostenibilidad. Estos escenarios ponen de manifiesto cómo la planificación a escala local repercute en el desarrollo a escala regional. Las variables que permiten evaluar los tres escenarios propuestos son: el incremento de la densidad urbana, la movilidad regional y la preservación del medioambiente. De acuerdo con estos principios, las tres propuestas cumplen con los objetivos nacionales de previsión de suelo residencial y productivo:

- Escenario de la densificación. Esta estrategia está de acuerdo con las políticas de reforma de los distritos ferroviarios desarrolladas por el Gobierno neerlandés. El incremento de la densidad urbana en estos sectores está relacionado con el de la movilidad, garantizando así la viabilidad del servicio.

- Escenario de la red. Este escenario consiste en la formación de redes urbanas con densidades inferiores al caso anterior aunque más diversas. La metrópolis es una realidad urbana heterogénea pero con una coherencia programática global. Este escenario ofrece la mayor diversidad de emplazamientos. La calidad del sector depende de la accesibilidad, el diseño arquitectónico y la integración de usos residenciales, recreativos y laborales.

- Escenario de la sostenibilidad. El objetivo de este escenario es el desarrollo sostenible. Está basado en la densificación de áreas urbanas existentes con criterios de mixtura funcional y preservación de los valores paisajísticos existentes.

El proyecto Stedenbaan se reformula como Stedenbaan Plus a partir de la integración, no sólo del servicio de trenes Sprinter pertenecientes a la NS, sino también de las estaciones de transporte público vinculadas a las redes de bus regional, suburbano, tren ligero y tranvía. Una de estas redes es la línea de tren ligero Randstadrail que conecta la ciudad de La Haya con Zoetermeer y Róterdam. Este servicio es inaugurado en 2006 sustituye algunas líneas ferroviarias obsoletas a escala regional. Entre los proyectos de regeneración urbana 
vinculados a la línea destaca el Beatrixkwartier ${ }^{39}$, en las proximidades de la estación central de La Haya (figura 4) y paralelo a la Utrechtsebaan (A12). El proyecto Stedenbaan Plus prevé que el 40 por ciento de toda la nueva urbanización del Zuidvleugel-Randstad se llevará a cabo en el entorno de los nodos de intercambio modal del transporte ferroviario.

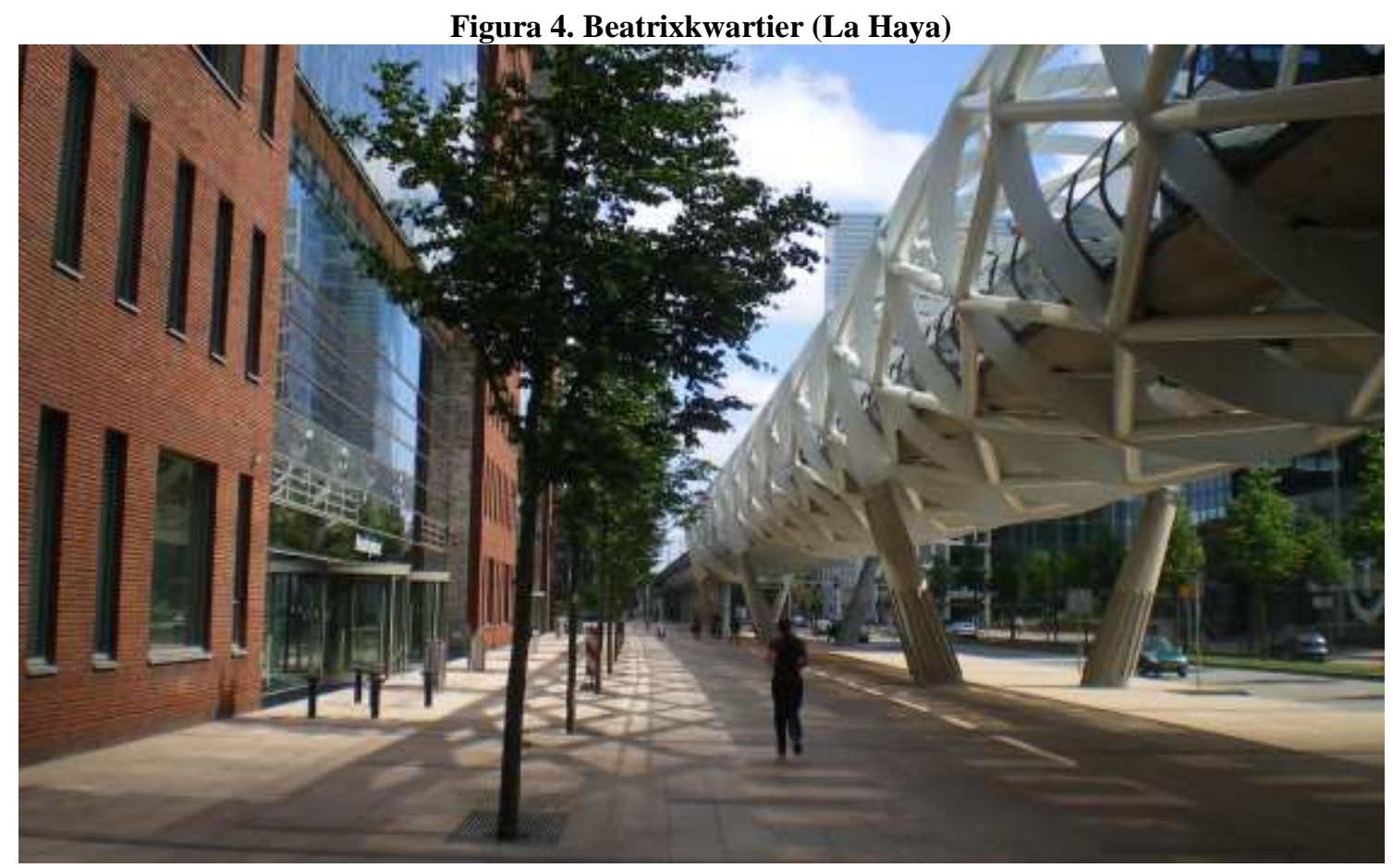

Imagen de la avenida Beatrixlaan en el nuevo distrito financiero Beatrixkwartier de La Haya con la estación de Randstadrail del mismo nombre, en viaducto, en primer término.

Fuente: Archivo del autor.

En conclusión, los nodos de transporte son espacios de nueva centralidad en el marco de los procesos de dispersión-contracción urbana en los Países Bajos. Estos nodos de intercambio modal están tradicionalmente vinculados a los sistemas de transporte público, y en particular al ferroviario. Programas como el Stedenbaan para el Zuidvleugel proponen la integración entre la red de transporte tranviario y la red urbana en un único sistema coordinado a escala provincial. El objetivo último es el desarrollo económico de la región metropolitana de Róterdam y La Haya, así como el posicionamiento internacional del Zuidvleugel en relación al Puerto de Róterdam y el aeropuerto de Ámsterdam-Schiphol, en base a la mejora de la calidad espacial en el entorno de los accesos y la eficiencia de la red de transporte.

Ahora bien, más allá de las mejoras introducidas en las redes de transporte, la consolidación de esta nueva estructura policéntrica depende de las oportunidades de desarrollo urbano de estos enclaves. El potencial del nodo del transporte como centro urbano podría evaluarse de acuerdo con criterios cuantitativos y cualitativos relacionados además, con la morfología urbana y las dinámicas productivas. En este sentido, es necesario evaluar la centralidad potencial de estos nodos a partir de la complementariedad de tres lecturas temáticas del

\footnotetext{
${ }^{39}$ El Beatrixkwartier (La Haya), diseñado por el arquitecto Joan Busquets, está ordenado en torno al eje Beatrixlaan alberga las sedes de algunas de las empresas más importantes del país como el National Nederlanden, TNT, ING o Siemens, entre otras. Este polo terciario está localizado en las proximidades de Den Haag CS y es accesible, además de mediante el sistema de tren ligero Randstadrail, por la autopista A12 (La Haya- Frontera alemana).Uno de los iconos arquitectónicos del distrito es el viaducto de la estación homónima, diseñada por los arquitectos Zwarts \& Jansma, en forma de malla tubular.
} 
territorio Randstad-Holland: la metrópolis habitable, en referencia a la morfología y la calidad de vida de la red urbana; la metrópolis activa, en relación a la diversidad y densidad de actividad que ocupa el territorio; y finalmente, la metrópolis conectada, relacionada con la complementariedad entre las diferentes redes de transporte.

\section{Criterios de centralidad metropolitana}

\section{La metrópolis habitable}

\section{Densidad urbana}

El Randstad-Holland es una de las regiones urbanas más densamente pobladas del occidente europeo (figura 5). La densidad media de la región es de 1.500 habitantes por kilómetro cuadrado, 393 habitantes por kilómetro cuadrado de media en los Países Bajos. Estos datos demográficos no son coyunturales sino que el desequilibrio en la distribución de la población es una cuestión endémica de la red urbana del delta desde sus orígenes.

Figura 5. Densidad de población en relación a la red de transporte terrestre

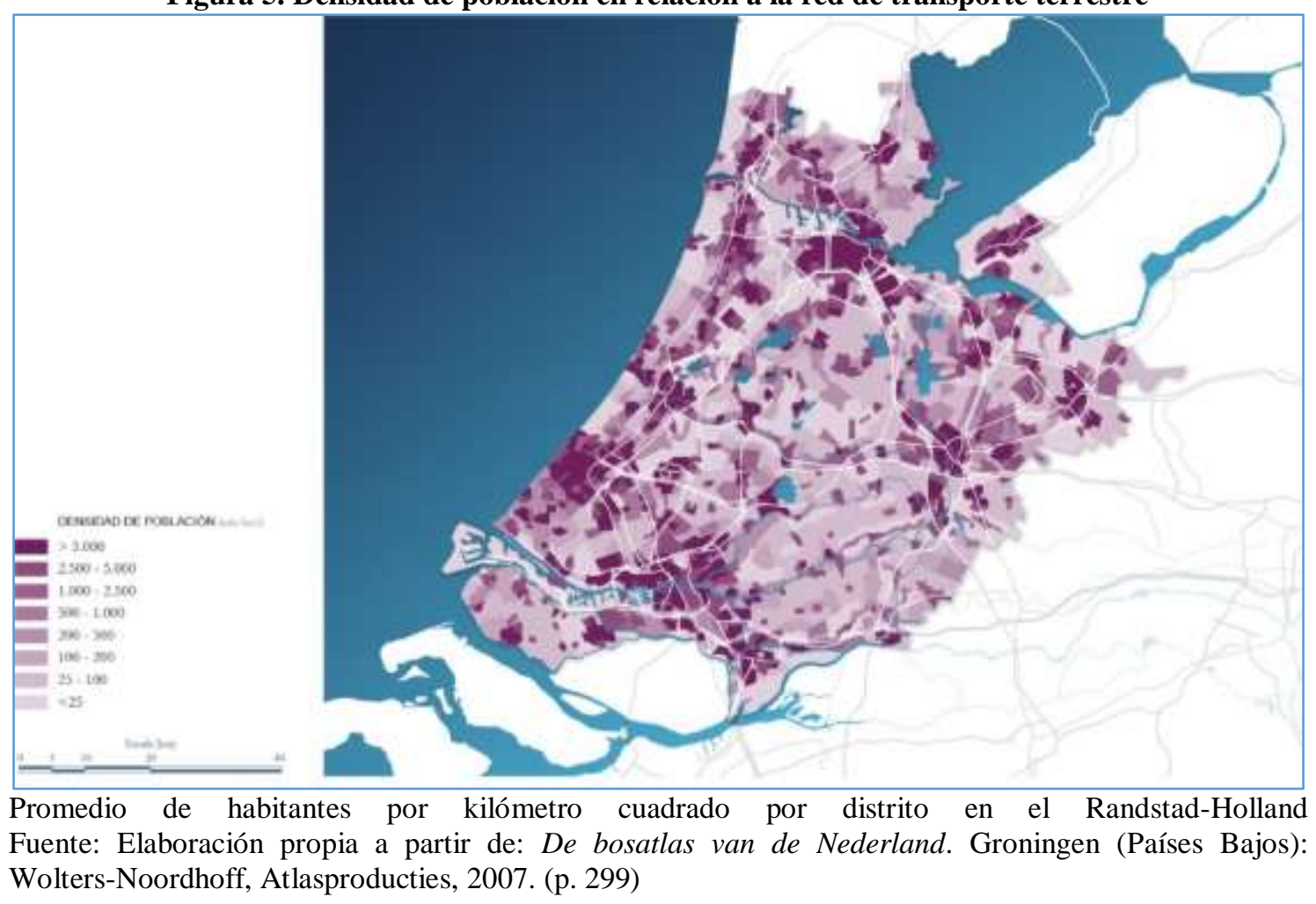

En el siglo XVIII, el 28 por ciento de la población neerlandesa habitaba en las principales ciudades del oeste: Ámsterdam, Haarlem, Leiden, La Haya, Delft, Róterdam, Dordrecht, Gouda y Utrecht. Esta proporción se mantuvo prácticamente estable hasta principios del siglo $\mathrm{XX}^{40}$. En la actualidad, la metrópolis del delta está habitada por 7,1 millones de personas

\footnotetext{
${ }^{40}$ Brand, 2011, p. 76.
} 
(42,3 por ciento de la población de los Países Bajos) y ocupa sólo el 20 por ciento de la superficie del país ${ }^{41}$.

Si se analiza el gráfico la distribución de la densidad población a partir de la configuración de la red de transporte (figura 5), es posible apreciar una correspondencia entre la densificación de la red urbana y la estructura de la red de ferrocarril. Esta relación se pone de manifiesto en corredores como la Oude Lijn [Línea antigua] entre Castricum y Róterdam, o la línea AlmereUtrecht, vía Hilversum, en dirección norte-sur. En dirección este-oeste, los cordones urbanos se sitúan en paralelo a las principales vías de comunicación acuática, como el curso del Oude Rijn entre Utrecht y Leiden, o el Waal entre Gorinchem y el Puerto de Róterdam. La correspondencia entre los corredores ferroviarios y los asentamientos pone de manifiesto el carácter vertebrador de red ferroviaria neerlandesa en la consolidación del policentrismo urbano.

\section{Diversidad de tejidos urbanos}

El Randstad-Holland es, tal y como demuestra la distribución de la población en el territorio, una metrópolis heterogénea en cuanto a su configuración espacial. En las primeras etapas de consolidación de la estructura urbana del delta, la frontera física entre el núcleo urbano y el medio rural está determinada por la infraestructura defensiva: el recinto amurallado. A medida que la interdependencia entre ciudad y entorno se intensifica, se incrementa también la diversidad de espacios de transición entre ciudad y campo. La heterogeneidad del paisaje urbano del delta es la consumación de las aspiraciones vitales de sus habitantes en cada momento histórico. En consecuencia, el Randstad-Holland es una realidad urbana flexible, al servicio de las necesidades coyunturales tanto espaciales como funcionales. Un ejemplo de esta flexibilidad es la progresiva polderización o recuperación de terreno lacustre en el IJsselmeer. En la actualidad, los procesos de suburbanización territorial contribuyen a la homogeneización del paisaje urbano del delta.

La distribución de los diferentes tipos de tejido urbano en el Randstad-Holland pone de manifiesto el policentrismo y diversidad de la metrópolis (figura 6). Si se agrupan los diversos tipos de medios residenciales en dos categorías: urbana (centro urbano, exterior de centro urbano, verde urbano y área de trabajo), y rural (centro rural, medio rural), la relación entre la infraestructura de transporte y la red urbana policéntrica resulta más inteligible. Se hace evidente la existencia de una lógica de conexión de los principales centros a escala regional, donde la primera periferia urbana concentra la mayor densidad de ejes de transporte. A escala local, sin embargo, no es tan evidente la correspondencia entre la ubicación del tejido urbano y las redes de comunicación de altas prestaciones, puesto que en muchos casos, el desarrollo de la red urbana se sustenta en estructuras de la movilidad de menor alcance como por ejemplo el sistema tranviario o de ferrocarril ligero.

\footnotetext{
${ }^{41}$ TNO. TNO-rapport: de top 20 van Europese stedelijke regio's: Randstad Holland in internationaal
} perspectief. Delft: Randstad Regio, 2010. p. 19. 
Figura 6. Diversidad de tejidos urbanos en el Randstad-Holland

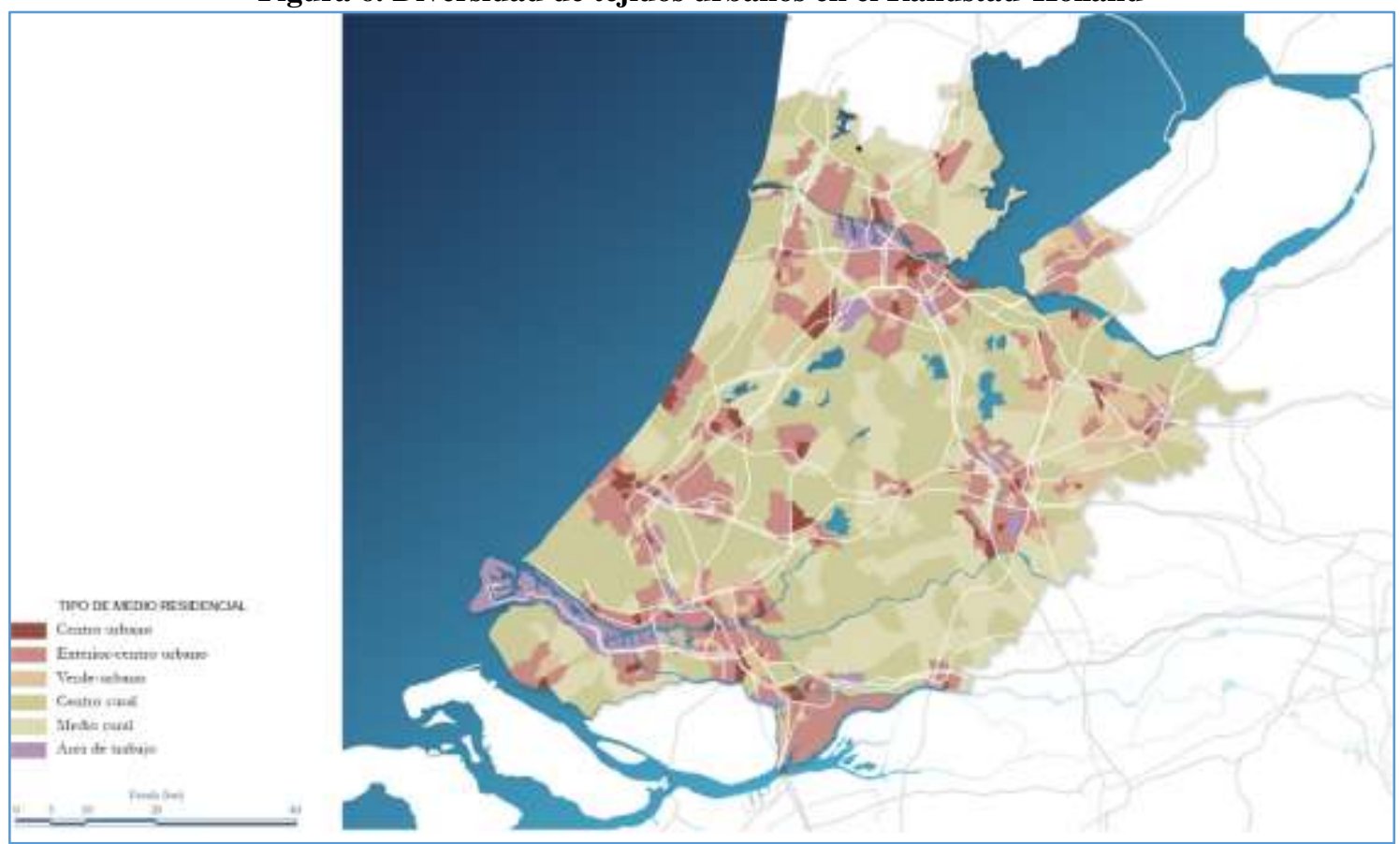

Tipos de medios residenciales en el ámbito del Randstad-Holland en relación a la red de transporte terrestre viaria y ferroviaria.Fuente: Elaboración propia a partir de: De bosatlas van de Nederland. Groningen (Países Bajos): Wolters-Noordhoff, Atlasproducties, 2007. (p. 226)

\section{Calidad de vida urbana}

Además del número de personas que constituyen una comunidad y la forma en que esta comunidad se organiza (densidad y tipo de tejido residencial) hay que considerar otro aspecto fundamental en la relación entre individuo y hábitat: la calidad de vida urbana. Existen dos aproximaciones teóricas al concepto de Calidad de vida urbana: desde una óptica geográfica, basada en factores cuantitativos y objetivos externos al individuo, como por ejemplo el número de bienes y servicios a disposición de los habitantes de un territorio. Una segunda aproximación, más sociológica, se basa en criterios cualitativos y subjetivos, internos al individuo, como por ejemplo la percepción que el ciudadano tiene de su entorno y de los bienes servicios a su alcance ${ }^{42}$.

La calidad de vida urbana vinculada a la ordenación espacial implica la adaptación del medio a las necesidades de una comunidad teniendo en cuenta aspectos relacionados con: el medio natural (ecológicos), el medio urbano (arquitectura), el equipamiento (servicios), y la organización de los elementos urbanos en el espacio (morfología). El concepto de Calidad de vida urbana ha centrado la política espacial neerlandesa de las últimas décadas, tanto a escala nacional como local. La IV Nota (1988) relaciona desarrollo urbano y calidad de vida con el objetivo de mejorar la competitividad de los centros urbanos del Randstad-Holland. La noción de Calidad de Vida Urbana, ha evolucionado en la planificación urbanística neerlandesa ${ }^{43}$

\footnotetext{
${ }^{42}$ LEVA, Germán. Indicadores de calidad de vida urbana: teoría y metodología. Buenos Aires: Universidad Nacional de Quilmes, 2005.

${ }^{43}$ De acuerdo con la $V$ Nota los 7 criterios que determinan la calidad espacial son:

- Diversidad espacial. Promoción del contraste entre campo y ciudad. La diversidad de espacios urbanos y paisajes preservando el carácter y los valores de cada medio.

- Funcionalidad económica y social. Planificación integral de las funciones básicas: vivir, trabajar, desplazarse y ocio.
} 
desde una visión estrictamente medioambientalista a una más integral que implica diversidad, tanto de la estructura espacial principal como la escala doméstica.

El número de indicadores que participan del concepto de Calidad de Vida Urbana es muy extenso. Entre otros, se pueden considerar aspectos como la asistencia social, el transporte público, la política cultural, la movilidad, la seguridad urbana, etc. Sin embargo, desde la óptica de la ordenación física del territorio, se estiman dos criterios objetivos: en sentido positivo el acceso a los servicios básicos y la relación entre el lleno y el vacío urbano, y sentido negativo la incompatibilidad funcional de los usos del suelo. Es decir, la Calidad de Vida Urbana, en este caso, se analiza a partir de la relación de proximidad-lejanía al equipamiento urbano, el espacio público de calidad y la actividad industrial molesta.

Figura 7. Calidad de Vida Urbana (CVU) en relación a la red de transporte terrestre

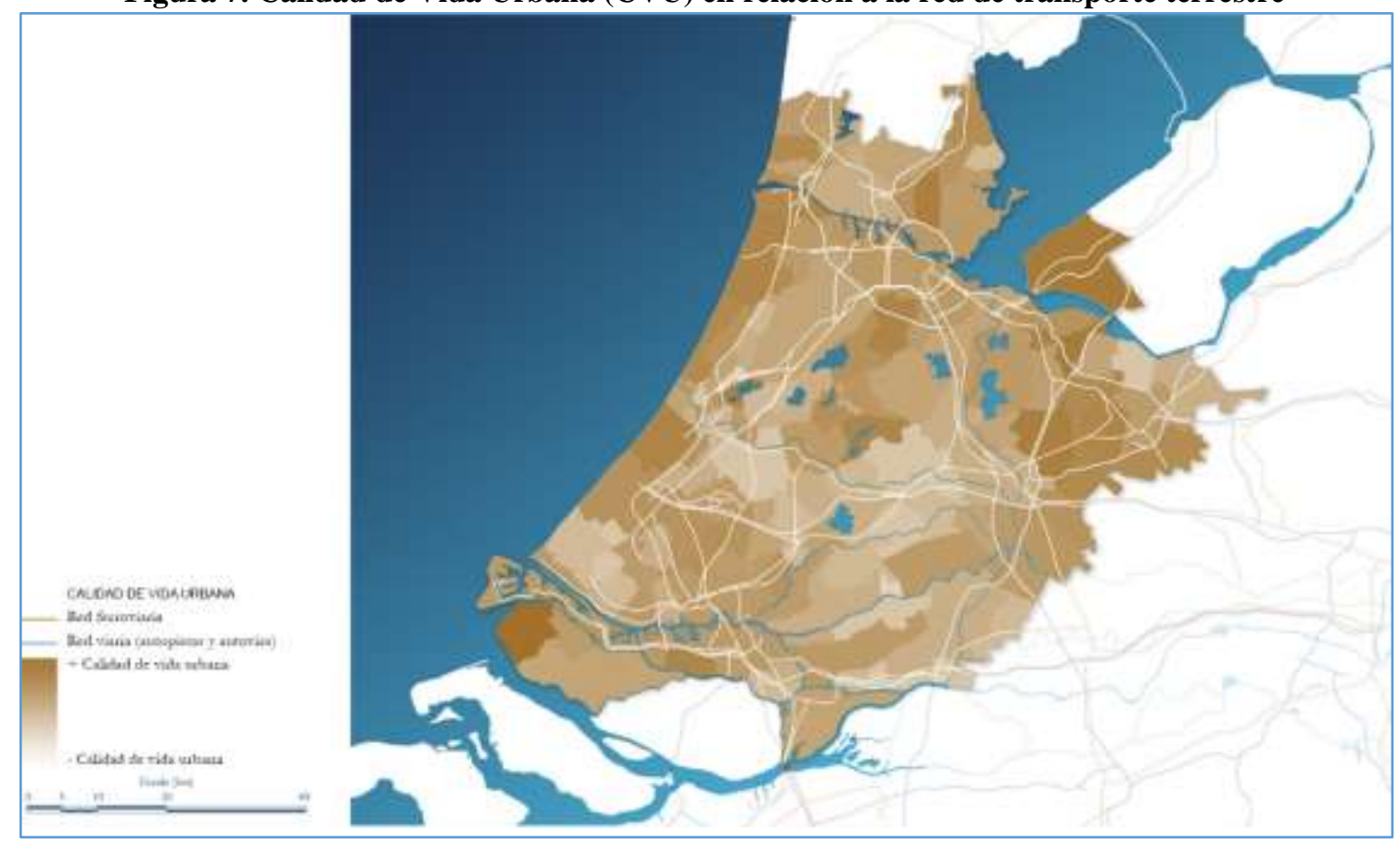

Calidad de Vida Urbana en el Randstad-Holland de acuerdo con el criterio de proximidad a servicios básicos, áreas de recreo y distritos industriales

Fuente: Elaboración propia a partir de: De bosatlas van de Nederland. Groningen (Países Bajos): WoltersNoordhoff, Atlasproducties, 2007. (p. 330)

El papel de la red de transporte en la distribución de la Calidad de Vida Urbana en el delta es contradictorio (figura 7), puesto que es un agente que garantiza el derecho a la movilidad de los individuos y simultáneamente es un factor de atracción de actividad productiva, en algunos casos, incompatible con los usos residenciales.

\footnotetext{
- Diversidad cultural. Comunidades e individuos deben disponer de los medios adecuados para su desarrollo singular, por lo tanto, debe haber espacio disponible para la diversidad de actividades.

- Igualdad social. Todos los habitantes deben tener la oportunidad de disfrutar de una vida saludable. Las estrategias se basan en frenar los agravios entre suburbios ricos y centros urbanos pobres, permitiendo que las clases sociales en riesgo de exclusión social dispongan de acceso a la vivienda, trabajo, movilidad y recreo.

- Sostenibilidad. Los valores de los sistemas ecológicos se deben preservar y restaurar. El desarrollo económico, social y cultural es compatible con una estructura integrada urbana-rural.

- Atractivo. El mantenimiento del atractivo urbano y rural es una obligación cultural.

Escala humana. El espacio debe ordenarse de acuerdo con las demandas y la percepción de los ciudadanos. La escala humana no tiene que verse afectada por las grandes infraestructuras o la magnitud de la arquitectura. El espacio público puede ser una estrategia de integración de ambas escalas.
} 
A escala regional, puede apreciarse cierta asimetría en la distribución de la Calidad de Vida Urbana entre el Noordvluegel y el Zuidvleugel (figura 7), siendo el índice de Calidad significativamente superior en el Ala norte, debido a la densidad de equipamientos existentes en la ciudad de Amsterdam, la mayor interacción entre medios urbanos y naturales entre el IJ y el Groene Hart, y una estructura económica más diversificada basada en el sector terciario y cuaternario, frente a la dependencia de la actividad logística portuaria en el Ala Sur.

\section{La metrópolis activa}

El Randstad-Holland es, desde el punto de vista económico, una de las regiones urbanas más dinámicas del occidente europeo. Esta metrópolis concentra prácticamente el 50 por ciento del Producto interior bruto nacional neerlandés ${ }^{44}$. Cabe destacar, sin embargo, una distribución asimétrica en la estructura interior de la región puesto que el dinamismo del Noordvleugel (Ámsterdam) supera al Zuidvleugel (Róterdam-La Haya) ${ }^{45}$. Esta asimetría es consecuencia la diversificación económica en el sector norte, apoyada en la presencia de actividades productivas de alta calidad, industria de capital intensivo y el dinamismo del hub logístico del AA-Schiphol. El Zuidvleugel, en cambio, depende en mayor grado del sector de la logística y la distribución cuyo centro de operaciones es el Puerto de Róterdam.

La estructura urbana policéntrica del oeste neerlandés se basa en dos aspectos: el desarrollo y eficiencia de la red del transporte y la especialización funcional de los centros urbanos. Las grandes ciudades del Randstad-Holland han asumido un rol exclusivo que les permite competir a escala internacional y local sin entrar en conflicto con los núcleos próximos. La Haya es la ciudad de la paz, la justicia y la seguridad; Róterdam es el centro logístico portuario; Utrecht es el $h u b$ del conocimiento y el nodo de la red terrestre; y finalmente la región metropolitana de Ámsterdam es la sede de grandes empresas multinacionales y destino turístico preferente. La hiperespecialización, no obstante, hace vulnerables a estos nodos urbanos a las oscilaciones económicas globales. En la actualidad, el carácter polifuncional es uno de los aspectos en los que incide la planificación espacial neerlandesa con el objetivo de asegurar la fortaleza económica de la metrópolis, y por extensión del país. En este sentido, los planes estratégicos de desarrollo urbano apuestan por reforzar el papel de Ámsterdam como gran centro urbano, complementario al mayor nodo logístico y de ocupación del país: el Aeropuerto Internacional de Schiphol.

\section{Densidad de actividad productiva}

En el año 2015, el número total de empleados en los Países Bajos era de 8,9 millones de personas, de los que prácticamente el 50 por ciento pertenecía al Randstad-Holland, según el Centro Nacional de Estadística (CBS). Este dato manifiesta el potencial de la región como motor económico nacional pero también el grado de desequilibrio en la distribución de la

\footnotetext{
${ }^{44}$ El PIB de los Países Bajos era de 528.990 millones de euros y en el Randstad-Holland de 241.191 en 2011. Los datos estadísticos actualizados para 2014 fijan el PIB nacional en 662.770 millones de euros.

${ }^{45}$ El promedio de crecimiento anual del Producto Interior Bruto regional en el periodo 1995-2005 (periodo en el que se implantan las políticas de integración de la movilidad y usos del suelo) es de 3,2 en el Noordvleugel y de 2,1 en el Zuidvleugel, el promedio en el Randstad-Holland es de 2,7; 3 décimas superior a la media neerlandesa. Otro dato significativo que revela el dinamismo económico del Ala Norte frente al Ala Sur es el dato de empleo de los principales centros urbanos, mientras Róterdam perdía 12.524 puestos de trabajo en el período 2010-2014, la ciudad de Ámsterdam ganaba 24.563 puestos de trabajo, especialmente en los campos de la investigación (29,9 por ciento), la cultura, el deporte y la recreación (11,1 por ciento) y la información y la comunicación $(8,7$ por ciento), de acuerdo con los datos actualizados de estos Ayuntamientos.
} 
actividad en este territorio. A escala local, la distribución de empleados entre el Noordvleugel (52 por ciento) y Zuidvleugel (48 por ciento) es prácticamente equivalente. La distribución de la masa laboral en el Randstad-Holland reproduce la estructura tradicional del anillo urbano entorno al vacío agrícola del Groene Hart. Los principales núcleos urbanos: Ámsterdam, la Haya, Róterdam y Utrecht; concentran las mayores densidades de la región. Esta configuración resulta obvia atendiendo a los valores de densidad demográfica y compacidad urbana analizados en el apartado anterior. De acuerdo con la figura 8, en el Noordvleugel, la intensidad y proporción de empleos respecto a residentes es significativamente superior al Zuidvleugel. A escala regional, el equilibrio residencial-laboral en el sector sur de Ámsterdam, entre Duivendrecht y el AA-Schiphol, es superior al del centro histórico.

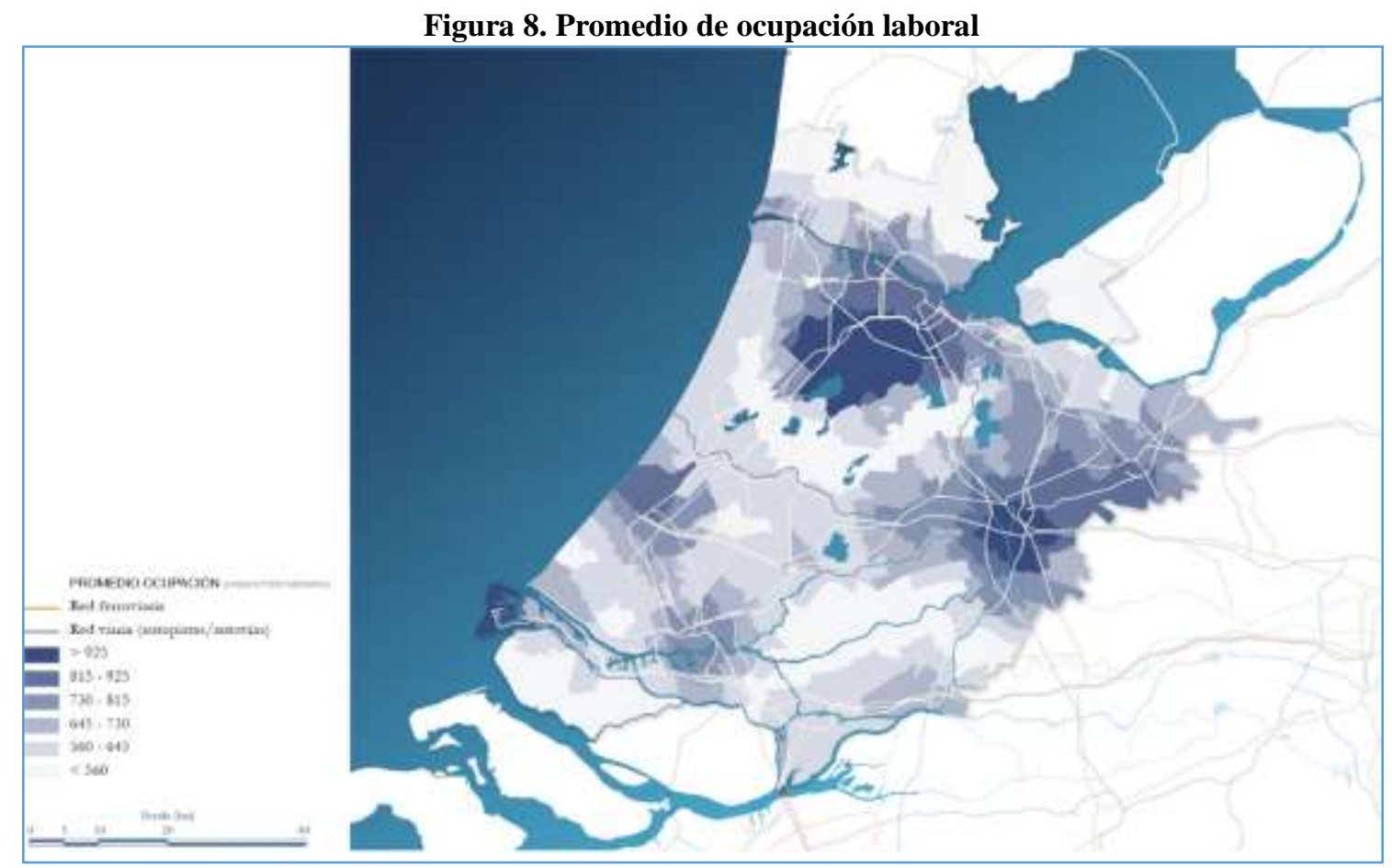

Promedio de puestos de trabajo/1.000 habitantes de 15 a 64 años en relación a red de transporte terrestre viaria y ferroviaria

Fuente: Elaboración propia a partir de: De bosatlas van de Nederland. Groningen (Países Bajos): WoltersNoordhoff, Atlasproducties, 2007. (p. 413)

Si se analiza la relación existente entre el número de residentes y puestos de trabajo de un sector y la red del transporte pueden extraerse conclusiones a escala regional y local (Figura 8). A escala del Randstad-Holland, los centros de intercambio modal y logística del Noordvleugel: AA-Schiphol y el hub de la ciudad de Utrecht actúan como catalizadores regionales. Por otra parte, los índices de empleo en los corredores infraestructurales este-oeste del Zuidvleugel son superiores, de acuerdo con el análisis realizao. A escala local, los ejes del transporte irradian actividad desde el centro histórico hacia la periferia urbana: Utrecht, Ámsterdam, La Haya, Gorinchem, etc.

\section{Diversidad de actividad productiva}

Los Países Bajos son una de las economías más dinámicas, abiertas y competitivas de la Unión Europea, con unas tasas de exportación de bienes y servicios que alcanzan el 82,9 por ciento del Producto Interior Bruto (2015), de acuerdo con los datos del Banco Mundial. Los factores que tradicionalmente han impulsado la economía neerlandesa son: la condición de 
nodo imprescindible de la red europea de transporte y el dinamismo del sector primario, especialmente vinculado al cultivo hortícola y la producción alimentaria. ${ }^{46}$ En la actualidad el principal motor de la economía neerlandesa por número de empleados es el sector terciario que comprende la actividad comercial, financiera, logística y las actividades sin ánimo de lucro. Todos estos sectores se benefician de las conexiones directas con los grandes puertos nacionales. Asimismo, existe una concentración significativa de centros relacionados con el denominado como cuarto sector: basado en el conocimiento y el desarrollo tecnológico, especialmente en las grandes capitales. Sólo en la Región Metropolitana de Ámsterdam, el 26,6 por ciento de las nuevas empresas establecidas en 2014 pertenecían a este sector, según datos del Ayuntamiento.

Figura 9. Nivel de heterogeneidad funcional en relación a la red de transporte terrestre

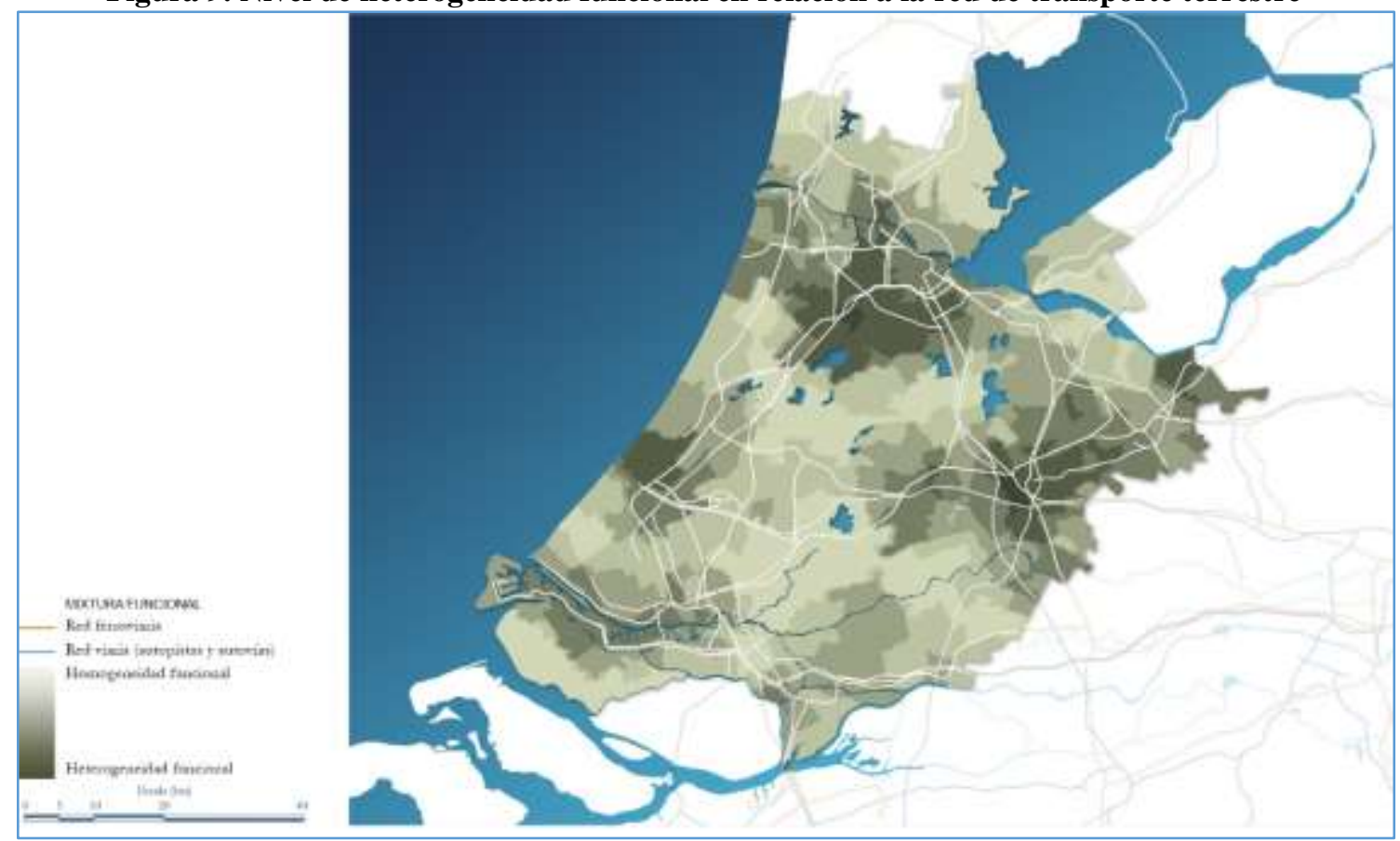

Mapa elaborado a partir de la combinación de dos variables: la densidad de empleo y la diversidad de actividad en el Randstad-Holland. Los sectores con mayor intensidad son aquellos en los que se concentra el mayor número de empleos en los principales sectores productivos de los Países Bajos: sector de servicios a empresas, servicios sociales y no productivos, servicios al consumidor, sector industrial, sector del conocimiento y sector logístico.

Fuente: Elaboración propia a partir de: De bosatlas van de Nederland. Groningen (Países Bajos): Wolters-Noordhoff, Atlasproducties, 2007. (p. 440-442)

A escala regional, cabe destacar la asimetría existente entre el Noordvleugel y el Zuidvleugel (figura 9). El eje Ámsterdam-Utrecht, en el norte, concentra la mayor mixtura funcional, frente al corredor La Haya-Róterdam. Las grandes capitales siguen siendo el motor económico del Randstad-Holland, e influyen en núcleos vecinos como es el caso del sistema Ámsterdam-Haarlem, Utrecht-Woerden o La Haya-Delft. A escala local y de acuerdo con la Figura 9, la diversidad de la actividad se encuentra en la primera corona de las grandes capitales. Como en el caso de Ámsterdam, donde el Ring A10 (autopista de circunvalación) establece el límite entre dos calidades de mixtura e intensidad funcional, en parte debido al

\footnotetext{
46 Aunque los Países Bajos ocupan el tercer lugar en la clasificación de países exportadores de productos relacionados con la horticultura y la industria alimentaria, sólo el 4 por ciento de la población neerlandesa está ocupada en este sector gracias al alto nivel de mecanización del trabajo agrícola, según datos de la Oficina Nacional de Estadística (CBS).
} 
desplazamiento de la actividad productiva hacia el suroeste y en concreto al Aeropuerto de Ámsterdam-Schiphol.

\section{La metrópolis conectada}

Desde las primeras etapas de colonización, el delta neerlandés se consolida como uno de los nodos imprescindibles de las rutas comerciales entre el Atlántico y Centroeuropa, en dirección este-oeste, a través del curso de grandes ríos como el Rin; y entre el Báltico y la Europa meridional, a través de un sistema interior de lagos y canales cuyo objetivo era evitar la violencia de los temporales del Mar del Norte. El desarrollo de la red fluvial va, por lo tanto, vinculado a la "construcción" del territorio habitable y las oportunidades de conexión. Los puertos en su papel de nodos de intercambio modal actúan como condensadores de actividad y organizan la estructura urbana del delta. Durante los siglos XIX y XX, la implementación de otras redes de transporte, ferroviarias y viarias a escala regional y local, fortalecen este sistema de relaciones entre ciudad y territorio (figura 10).

Figura 10. Ámbito de servicio de las redes viaria y ferroviaria de altas prestaciones

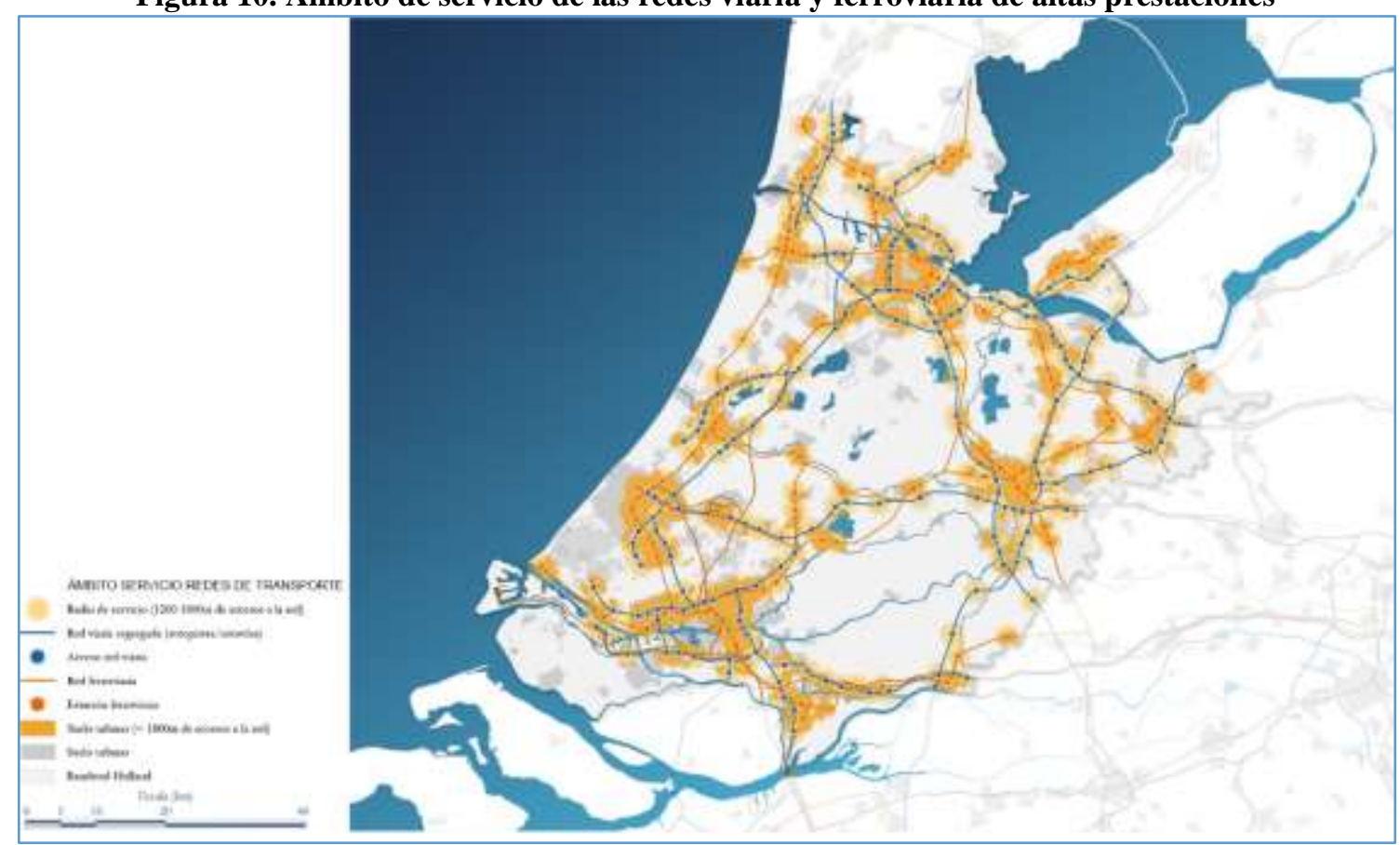

Suelo urbano accesible en un radio de 500 metros, 1.200 metros y 1.800 metros en torno a las estaciones ferroviarias y los accesos a la red de autopistas.

Fuente: Elaboración propia.

El incremento de la movilidad en los Países Bajos experimenta un crecimiento sin precedentes a partir de la segunda mitad del siglo XX. Este desarrollo es posible fundamentalmente gracias a dos factores: la socialización del uso del automóvil, que acelera el cambio de los patrones de ocupación del territorio, y las mejoras en las redes de transporte que permiten aumentar la capacidad y eficiencia de los corredores infraestructurales, tanto de personas como de mercancías. Ahora bien, además de la capacidad de las redes, también se incrementa la necesidad de desplazamiento como consecuencia de la dispersión de las actividades urbanas en el territorio. Los viajes para acudir al centro de trabajo y a los centros 
educativos suponen en 40 por ciento de la movilidad obligada en el Randstad-Holland, y prácticamente el 75 por ciento del total de trayectos se realizan en vehículo privado ${ }^{47}$.

\section{La red viaria}

La red ferroviaria toma el relevo del sistema de transporte fluvial y marítimo durante la segunda mitad del siglo XIX. Poco a poco los sistemas de transporte individual: bicicleta, ciclomotor, automóvil, etc. se convierten en una alternativa asequible y eficiente para la movilidad de la población neerlandesa. Sin embargo, la inversión de las estadísticas de uso entre los medios colectivos e individuales de transporte obliga al Gobierno neerlandés a reformular la estructura de las redes del transporte terrestre. Desde la inauguración del primer tramo de autopista en el Randstad-Holland en los años 30, el desarrollo de la red viaria ha sido imparable ${ }^{48}$ frente al estancamiento del número de kilómetros de red ferroviaria, prácticamente estable desde los años 70.

La distribución del tráfico en la red viaria de altas prestaciones (autopistas y autovías) en el Randstad-Holland revela el nivel de saturación del sistema. Prácticamente todos los tramos que discurren por esta metrópolis tienen un volumen de servicio alto o muy alto, en comparación con la media del resto de autopistas nacionales (figura 11). Por otra parte, las grandes capitales actúan como polos de atracción del tráfico a escala regional e interprovincial. En la araña de IMD (Índice Medio Diario de tráfico) las bifurcaciones de la red son los nodos donde, a causa de la distribución del tráfico, el grado de saturación disminuye, como por ejemplo en los nodos entre: A4-A44 (Knooppunt Burgerveen), A12A20 (Gouda), A27-A28 (Knooppunt Rijnsweerd), A1-A27 (Knooppunt Eemnes), y A7- A8 (Knooppunt Zaandam).

La congestión de la red viaria neerlandesa es una realidad no por habitual menos incómoda para sus usuarios, pese a las inversiones llevadas a cabo en su mejora y ampliación. Como resulta obvio, el Randstad-Holland concentra el mayor número de congestiones de tráfico del país. Las dos variables que permiten evaluar el nivel de gravedad de la congestión viaria son la longitud del atasco y su prolongación en el tiempo. Los tramos viarios más congestionados se sitúan en: el periférico y las radiales de acceso de la ciudad de Ámsterdam, los ejes que confluyen en la ciudad de Utrecht, en particular la autopista A2, y finalmente en el tramo entre Róterdam y La Haya. Las medidas para resolver estos niveles de congestión pasan por actuaciones puntuales de ampliación de la capacidad de la red (aumentar el número de carriles) o medidas restrictivas del tráfico como la limitación de la velocidad o la prohibición de la circulación de transporte pesado.

\footnotetext{
${ }^{47}$ Veldhuis, 2009, p. 19.

${ }^{48}$ La red viaria neerlandesa tiene una longitud total de 132.397 kilómetros, de los cuales 122.416 kilómetros pertenecen a la red local y regional. La red nacional de carreteras está compuesta por un sistema de autopistas (A-autosnelwegen) y vías interprovinciales ( $N$-wegen). La red de autopistas dispone de una longitud de 2.346 kilómetros. Las políticas de movilidad del gobierno neerlandés se centran en el incremento de la capacidad de la red existente más que en la construcción de nuevos ejes de conexión. Wolters-Noordhoff, 2007, p. 459.
} 
Figura 11. Nivel de saturación de la red de transporte terrestre en el Randstad-Holland

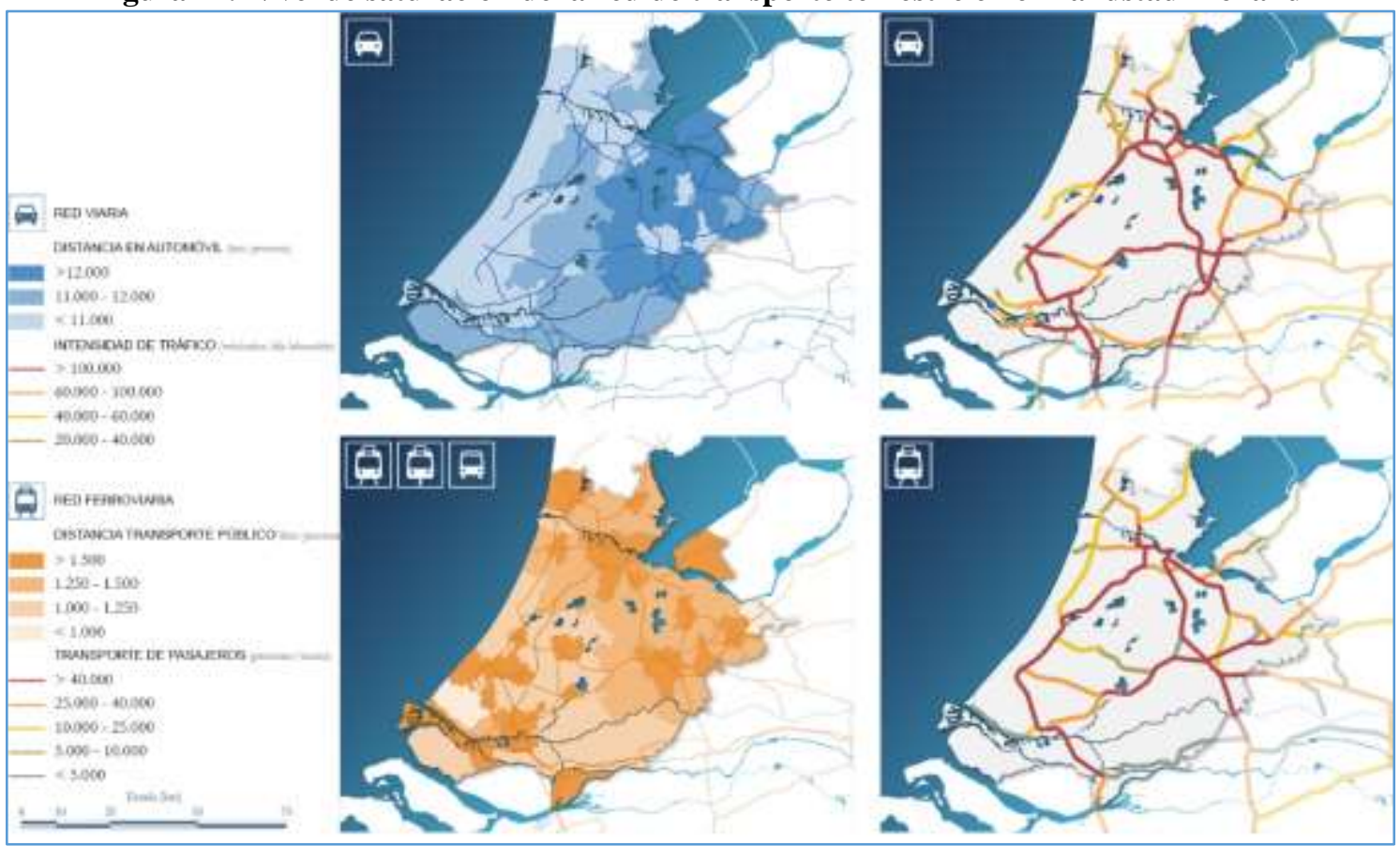

Distancia recorrida $(\mathrm{km})$ anualmente por persona en vehículo privado y transporte público en cada uno de los municipios del Randstad-Holland en el período de implementación de los proyectos de mejora de la red ferroviaria (1995-2002); araña de intensidad de tráfico en la red de autopistas y volumen de pasajeros por tramo de la red ferroviaria en el Randstad-Holland.

Fuente: Elaboración propia a partir de: De bosatlas van de Nederland. Groningen (Países Bajos):

Wolters-Noordhoff, Atlasproducties, 2007, (p. 459)

\section{La red ferroviaria}

Aunque el desarrollo de la red viaria en el Randstad-Holland a partir de la segunda mitad del siglo XX supone el dominio del vehículo privado sobre el resto de medios, la cuota del sistema ferroviario en el transporte de pasajeros es alta ( 8 por ciento $)^{49}$. Si se tiene en cuenta el número de usuarios desde la puesta en marcha del servicio en 1839 aparecen algunos episodios significativos como por ejemplo el descenso precipitado de la demanda durante la Segunda Guerra Mundial o el incremento durante las crisis del petróleo de los 70. Sin embargo, el salto cuantitativo más importante tiene lugar en los 90, prácticamente duplicando en una década el promedio de pasajeros de los 150 años anteriores, en parte, gracias a la introducción de un nuevo sistema tarifario integrado que incluye un título particular para estudiantes.

Los tramos de la red ferroviaria con mayor número de usuarios son los comprendidos en las rutas norte-sur entre las capitales del Zuidvleugel y Noordvleugel (figura 11). De este modo, la línea entre Ámsterdam y Róterdam vía Schiphol es la columna vertebral del transporte público del oeste del Randstad-Holland, a escala regional. En el sector oriental en cambio, se pone de manifiesto el sistema radial en torno a Utrecht como centro logístico, tanto a escala

\footnotetext{
${ }^{49}$ La red ferroviaria neerlandesa, gestionada por Pro-rail, dispone de una longitud de 2.031 kilómetros en 2015, de acuerdo con los datos de la Oficina Nacional de Estadística (CBS). El 75 por ciento de los habitantes de los Países Bajos vive en un radio inferior a 5 kilómetros de una estación de ferrocarril, según datos de la compañía ferroviaria (NS). La mayor parte de la red es mixta pasajeros/carga, pero hay algunas líneas exclusivas para el transporte de mercancías Betuweroute.
} 
regional como nacional ${ }^{50}$. La distribución de pasajeros en el sistema ferroviario, al margen de consideraciones cualitativas relacionadas con el servicio, depende además de: la configuración geométrica de la red, las características de los tejidos urbanos que conecta, morfológicas y funcionales; y la conexión con centros de intercambio modal multiescalar.

La consolidación de los accesos a las redes de transporte como nuevas centralidades metropolitanas depende tanto del volumen del flujo en el nodo como de la calidad del vicio de transporte público que suponga una alternativa viable al uso del vehículo privado. Del análisis del Randstad-Holland se deduce que la primera periferia urbana y, en particular, los corredores radiales y de circunvalación de las grandes capitales, concentran una elevada densidad de movimiento y actividad, así como un grado de heterogeneidad funcional y conectividad superior a la media, en un entorno urbano parcialmente consolidado. La oportunidad de estos espacios metropolitanos vinculados a la infraestructura de transporte como nuevas centralidades territoriales depende de la capacidad de propiciar el intercambio modal entre la movilidad regional (viaria y ferroviaria) y los sistemas locales que estructuran el movimiento: tanto público como privado. Pero principalmente la clave está en dejar de ser espacios de paso para convertirse en espacios de destino, capaces de gestionar tanto la interacción entre flujos de transporte como entre individuos.

\section{Conclusiones}

El planeamiento urbanístico neerlandés, a escala nacional, está centrado desde sus orígenes, en la gestión de los procesos de concentración - dispersión urbana, y en cómo estos procesos se orientan para la consolidación de una estructura policéntrica apoyada en los nodos de la red de transporte. La distribución de esta estructura nodal en el territorio del Randstad-Holland depende, entre otros aspectos, de la relación de equilibrio entre las dinámicas demográficas y económicas, tanto internas como externas al sistema. En este sentido, la integración de la red de transporte y la red urbana es una constante en los Memorándums de ordenación espacial neerlandeses o Notas. La coordinación de ambos sistemas permite mejorar la eficiencia energética en el transporte y preservar uno de los bienes más escasos de la región: el suelo libre.

A escala internacional, la centralidad de los Países Bajos en la red de transporte global está favorecida por un lado, por el desarrollo de los grandes puertos: el Aeropuerto Internacional de Ámsterdam-Schiphol y el Puerto de Róterdam; y por otro lado, por la especialización funcional de las grandes capitales. Sin embargo, el difícil acuerdo entre las administraciones a escala nacional, provincial, regional y local; cuyas competencias sectoriales están además, muy delimitadas, supone un obstáculo para el desarrollo y cohesión de la estructura urbana. En este sentido, la prosperidad de los nuevos centros de actividad del Randstad-Holland depende de su integración en el sistema urbano global y la mejora de la eficiencia del transporte a escala local. En el primer caso, tanto el sistema de transporte aéreo, encabezado por el AA-Schiphol, ${ }^{51}$ como la red acuática, apoyada en el Puerto de Róterdam ${ }^{52}$, son

\footnotetext{
${ }^{50}$ El transporte ferroviario de mercancías supone aproximadamente un 2 por ciento del total (2006). El tipo de mercancías transportadas son: productos a granel, combustible, minerales, productos químicos y agrícolas. La principal ruta de transporte de mercancías del sistema ferroviario neerlandés es la Betuweroute, nombrada de este modo porque su trazado discurre a lo largo de $160 \mathrm{~km}$ desde Róterdam hasta la frontera alemana en el este, a través del paisaje del Betuwe. La construcción comienza en 1996 y finaliza en 2007.

51 El Aeropuerto Internacional de Ámsterdam-Schiphol es el quinto aeropuerto de Europa en volumen de pasajeros (51 millones en 2009) mientras que ocupa el tercer puesto en la clasificación mundial en cuanto a pasajeros de vuelos internacionales.
} 
infraestructuras competitivas a escala continental. Sin embargo, la condición de hub logístico de la Deltametrópolis está comprometido por el tráfico terrestre. La congestión de la red viaria de altas prestaciones neerlandesa a escala local interfiere el transporte pesado a escala internacional. Asimismo, la deficiente inversión en la red ferroviaria de mercancías, podría poner en riesgo la primacía de los centros logísticos neerlandeses en la red europea de transporte.

En las últimas décadas del siglo XX, se produce en el ámbito del planeamiento urbanístico neerlandés un intenso debate sobre el futuro de la metrópolis del delta. La configuración tradicional del Randstad-Holland basada en un policentrismo urbano altamente jerarquizado e hiperespecializado está en cuestión. Otras formas de ordenación en forma de cinta urbana, apoyadas en la red de autopistas periféricas, compite con la constelación de centros históricos. El concepto de corredor centra el debate durante este periodo, desde una óptica tanto física como económica. Finalmente, se llega a una fórmula de consenso que reconoce el papel de los centros tradicionales como motores económicos en red con los nuevos nodos logísticos o de transporte. A lo largo de estas últimas décadas, se han llevado a cabo planes que integran movilidad y planeamiento territorial promoviendo el desarrollo coordinado de estos nodos, como por ejemplo el programa Stedenbaan. Una aproximación al fenómeno metropolitano basado en el corredor nodal, apoyado en el sistema de transporte público, que puede servir como modelo para otras regiones de características morfológicas similares.

Por otra parte, la intervención en el nodo de transporte no puede considerarse sin la renovación de su entorno, a escala regional, la actuación sobre un nodo afecta al sistema en su conjunto, tanto en la mejora del servicio de transporte como en la distribución de las actividades por el territorio. En este sentido, la cooperación entre administraciones competentes en materia de movilidad y planificación urbana, así como la participación ciudadana y agentes privados, es indispensable para el desarrollo coordinado de estos centros urbanos. La planificación integral de estos nodos de la red urbana y de transporte debería realizarse desde una perspectiva pluridisciplinaria, en la que intervengan profesionales de diferentes campos del conocimiento: ingeniería, geografía, sociología, ecología, etc., y multiescalar, creando un nuevo marco territorial de gestión que englobe la metrópolis policéntrica.

El Randstad-Holland es una entidad geográfica de consenso que se ha consolidado en el imaginario colectivo neerlandés en los últimos ochenta años. La permanencia del modelo urbano dependerá de la capacidad de adaptarse a las demandas presentes y futuras, así como de establecer unos instrumentos de gestión eficaces en favor de un desarrollo común en la diversidad. El Randstad-Holland nunca ha dispuesto de un organismo competente en la administración de la metrópolis. Sin embargo, las políticas de planificación urbana llevadas a cabo en las últimas dos décadas han estado dirigidas a la definición de unas estrategias de consenso transversal tanto en lo disciplinario como en la escala de ordenación. La fortaleza y debilidad del sistema policéntrico reside en la permanente necesidad de acuerdo, la creación de una entidad pública que gestione el sistema en su globalidad y la red de transporte en particular, podría contribuir a mejorar la competitividad económica de la Deltametrópolis en la red urbana europea.

\footnotetext{
${ }^{52}$ El Puerto de Róterdam ostenta el título de puerto más activo del mundo durante el periodo 1961-2002, en la actualidad superado por el puerto de Singapore y Shanghai. En el año 2011 ocupa el quinto puesto en cuanto a carga anual.
} 


\section{Bibliografía}

ATELIER ZUIDVLEUGEL. Space and line: a spatial survey for Stedenbaan 2010-2020, The South Wing of the Randstad. Nova Terra connected cities. La Haya: Nederlands Insitut voor Ruimtelijke Ordening en Volkshuisvesting NIROV, 2007, núm. febrero, p. 11-16.

BALZ, Verena; Schrijnen, Joost. From concept to Projects: Stedenbaan, The Netherlands. Bertolini, Luca (ed.); Curtis, Carey (ed.); Renne, John L (ed.). Transit oriented development: making it happen. London: Ashgate, 2009. Cap. 7, p. 75-90.

BERTOLINI, Luca; et al. Transit oriented development: making it happen. Curtis, Carey (ed.); Renne, John L (ed.). Farnham (Reino Unido): Ashgate, 2009. 291 p.

BLANK, Hilde; et al. Ontwerpen aan Randstad 2040. Ovink, Henk (ed. serie); Wierenga, Elien (ed.); Victor, Joseph (trad.). Róterdam: 010 publishers, 2009. 164 p.

BOEIJENGA, Jelte. Vinex: compactestadbeleid. Compacte stad extended: agenda voor toekomstig beleid, onderzoek en ontwerp. Ovink, Henk (ed. Serie); Wierenga, Elien (ed.); Open book (trad.). Róterdam: 010 Publishers. 2011, p. 24-34, col. Design and Politics, núm. 4.

BOELENS, Luuk (ed.); et al. Compacte stad extended: agenda voor toekomstig beleid, onderzoek en ontwerp. Ovink, Henk (ed. Serie); Wierenga, Elien (ed.); Open book (trad.). Design and politics. Róterdam: 010 Publishers, 2011. 352 p. núm. 4.

BOS, Pieter, et al. De bosatlas van de Nederland. Groningen (Países Bajos): WoltersNoordhoff, Atlasproducties, 2007. 560 p.

BOUWER, Inoek. Fixing the link: creating a strong, vital and attractive link between the Dutch central railway station and city centre. Director: Remon Rooij, Stevan van der Spek. Tesis de master. Delft university of technology, Nederlandse Spoorwegen, 2010. 249 p.

BUREAU ONDERZOEK EN STATISTIEK. Amsterdam in cijfers 2014. Amsterdam: Gemeente van Amsterdam, 2014. 596 p.

BRAND, Nikki. De opkomst van de Randstad: een verkenning volgens de rank-size rule (11de-21ste eeuw). OverHolland - architectonische studies voor de Hollandse stad. 2010, núm. 9, p. 69-81.

CAVALLO, Roberto. Spoorwegen in de Hollandse stad. OverHolland - architectonische studies voor de Hollandse stad. TU Delft. Amsterdam: Uitgeverij SUN. 2011, núm. 5, p: 4259.

DINGS, Mieke. Historisch perspectief 1900-2010. Ovink, Henk (ed.); Wierenga, Elien (ed.). En: Ontwerp en politiek. Róterdam: 010 publishers. 2009, núm. 1, p. 11-158.

DUINEN, Lianne van. Planning imagery: the emergence and developments of new planning concepts in Dutch national spatial policy. [s.1.] (Países Bajos): Lianne van Duinen, 2004. 332 p. 
FILARSKI, Ruud; Mom, Gijs. Van transport naar mobiliteit: de mobiliteitsexplosie (18952005). Zutphen (Países Bajos): Warlburg, 2008. vol. 2, 477 p.

HALL, Peter. The world cities. $3^{\mathrm{a}}$ edición. London: Weidenfeld \& Nicolson, 1984. 276 p. (1 edición: Londres: World university library, Weidenfeld \& Nicolson, 1966).

HALL, Peter; Pain, Kathy. Polycentric metropolis: learning from mega-city regions in Europe. Londres: Earthscan, 2006. 228 p.

TNO. TNO-rapport: de top 20 van Europese stedelijke regio's: Randstad Holland in internationaal perspectief. Delft: Randstad Regio, 2010.

VELDHUIS, Wouter; Paebens, Inge. Atlas van de snelwegomgeving: handreiking bij de structuurvisie voor de snelwegomgeving. Breda (Países Bajos): Ministerie van Volkshuisvesting, Ruimtelijke Ordening en Milieubeheer VROM, 2009. 223 p.

VENHOEVEN, Ton; van de Boomen, Tijs. De mobiele stad: wisselwerking van stad, spoor en snelweg. Róterdam: nai010 Uitgevers, 2012. 240 p.

VROM (Ministerie van Volkshuisvesting, Ruimtelijke Ordening en Milieubeheer). Vierde nota over de ruimtelijke ordening. La Haya: Uitgeverij Sdu, 1988-1990.

VROM. Sleutelprojecten ruimtelijke inrichting: rol van het Rijk en Tussenstand. La Haya: Uitgeverij SDU, 1991.

VROM (Ministerie van Volkshuisvesting, Ruimtelijke Ordening en Milieubeheer). Ruimtelijke verkenningen 1994: balans van de vierde nota ruimtelijke ordening (extra). Rijksplanologische dienst, La Haya: Uitgeverij Sdu, 1994.

VROM. Ambities voor de Deltametropool: eindrapportage interdepartamentaal project Deltametropool. Ministerie van Verkeer en Waterstaat La Haya: VROM, 2002. 79 p.

VROM (Ministerie van Volkshuisvesting, Ruimtelijke Ordening en Milieubeheer). Randstad 2040 startnotitie: naar en duurzame en concurrerende europese topregio. Ministerie van Verkeer en Waterstaat MVW. La Haya: Sdu uitgevers, 2008.

WAGENAAR, Cor. Town planning in the Netherlands since 1800: responses to enlightenment ideas and geopolitical realities. Róterdam: 010 publishers, 2011. 639 p.

ZANDBELT, Daan; Roo, Gert de; et al. Regio's in verandering: ontwerpen voor adaptiviteit. Kirkpatrick, John (trad.); Victor, Joseph (trad.). Róterdam: NAi utigevers, 2012. 224 p.

(C) Copyright: Joan Moreno Sanz y Estanislao Roca Blanch, 2016.

(C) Copyright Scripta Nova, 2016.

Ficha bibliográfica:

MORENO SANZ, Joan: ROCA BLANCH, Estanislao. La metrópolis del delta neerlandés. Crisis y actualización de un modelo urbano policéntrico. Scripta Nova. Revista Electrónica de Geografía y Ciencias Sociales. [En línea]. Barcelona: Universidad de Barcelona, 15 de agosto de 2016, vol. XX, $\mathrm{n}^{\circ}$ 542. <http://www.ub.es/geocrit/sn/sn-542.pdf>. ISSN: 1138-9788. 